\title{
Do catador ao doutor: um retrato da informalidade do trabalhador por conta própria no Brasil
}

From the waste picker to the physician: a portrait of the informality of the self-employed in Brazil

\author{
Carlos Eduardo Pinto Santiago \\ SEBRAE \\ Ana Maria Nogales Vasconcelos \\ Universidade de Brasília
}

\section{Abstract}

This paper aims to evaluate the degree of formalization of self-employed in Brazil. At a first moment a bibliographical review is made on studies that originated the concept of "informal sector". By exploring the operationalization of the concept, the author argues that the term "informal employment" reinforces the idea that there are cases where the self-employed can be regarded as formal. From the analysis of the evolution of data from National Survey by Household Sampling (PNAD 2009-2014), highlighting the fact that among adults and individuals living in urban areas only $16.1 \%$ are formal. Therefore, it is concluded that the rate of formalization of self-employment can be expanded and for this to occur it is essential to have a more accurate understanding of this heterogeneous occupational category which encompasses both waste pickers andphysicians.

\section{Keywords}

informality; self-employment; heterogeneity.

JEL Codes J21; J23; J10.

\section{Resumo}

O presente artigo tem por intuito avaliar o grau de formalização dos trabalhadores por conta própria no Brasil. Inicialmente, é feita uma revisão bibliográfica sobre os estudos que originaram o conceito "setor informal". Ao explorar a operacionalização do conceito, o autor argumenta que o termo "emprego informal" ratifica a ideia de que existem casos em que o trabalhador por conta própria pode ser considerado como formal. A partir da análise da evolução dos dados da Pesquisa Nacional por Amostra de Domicílios (PNAD 2009-2014), é traçado um panorama do trabalho por conta própria no Brasil, com destaque para o fato de que entre os individuos adultos e residentes em áreas urbanas, apenas $16,1 \%$ são formais. Conclui-seque a taxa de formalização do trabalho por conta própria pode ser ampliada, e para que isso ocorra é fundamental um conhecimento mais apurado sobre essa heterogênea categoria ocupacional, que engloba do catador ao doutor.

\section{Palavras-chave}

informalidade; trabalho por conta própria; heterogeneidade.

Códigos JEL J21; J23; J10. 


\section{Introdução}

O conceito e as variações do termo "informal" podem ser analisados a partir de uma ótica otimista, neutra ou pessimista. De acordo com Chen (2012), apesar dos debates e críticas, a economia informal continua como um conceito útil para agentes políticos, ativistas e pesquisadores devido ao fato de a realidade capturada ser ampla e significativa. A Organização Internacional do Trabalho (OIT) não hesitou em considerar o "setor informal", conceito chancelado por ela própria em 1972, como inadequado - senão enganoso - para refletir um fenômeno complexo e heterogêneo (ILO, 2002), epropôs novas formulações e estratégias de mensuração. Apreciações mais críticas, como a de Ramos (2007), questionam a utilidade analítica do conceito por acreditar que o mesmo é utilizado de forma arbitrária e flexível.

A trajetória conceitual que busca compreender o universo das atividades "informais" é tortuosa. Hugon (1997) e Noronha (2003) classificam o conceito como polissêmico, ou seja, dotado de diversos significados. Por outro lado, eventuais ambiguidades e a falta de consenso são atenuadas pelo fato de que essas características são habituais em todos os campos de debate das ciências sociais (Tokman, 1987).

Os estudos sobre informalidade costumam relacionar indistintamente o trabalho por conta própria com ainformalidade. Diante desse cenário, o presente artigo busca romper o paradigma de que todo trabalhador por conta própria é informal. Além desta seção introdutória, as ideias estão organizadas a partir da análiseda origem do conceito "setor informal", das diferentes abordagens teóricas (escolas de pensamento)sobre o fenômeno e das recomendações estatísticas recentes sobre emprego informal que consideram que alguns trabalhadores por conta própria podem vivenciar umasituação deemprego formal.

Por fim, é feita uma análise sobre o trabalho por conta própria urbano e adulto no Brasil a partir dos dados da Pesquisa Nacional por Amostra de Domicílios (PNAD 2009 e 2014). São expostos dados descritivos com o cruzamento entre a formalização e determinadas características sociodemográficas (sexo, idade, escolaridade, região de residência, etc.), bem como as diferenças entre os trabalhadores por conta própria formais dos informais, do ponto de vista da sua inserção no mercado de trabalho (tempo de ocupação, tipo de estabelecimento, tipo de atividade realizada, etc.). 
As considerações finais reportam a relevância do trabalho por conta própria para a agenda de desenvolvimento do país, bem como expõem as limitações do presente estudo e sugerem possibilidades de aperfeiçoamento para análises futuras que busquem aprofundar os conhecimentos acerca das relações entre o autoemprego e a informalidade.

\section{0 “informal” como setor: a origem do conceito}

Algumas considerações devem ser feitas antes de uma análise pormenorizada dos documentos que dão origem ao conceito. Em primeiro lugar, é preciso entender quais ideias dominavam o debate acerca das interfaces entre o desenvolvimento e as formas de inserção dos indivíduos no mundo laboral ao final da década de 1960 - dicotomia entre o tradicional e o moderno. Em seguida, é importante ressaltar o contexto histórico em que o conceito foi cunhado, marcado por mudanças de paradigmas no que diz respeito às diferentes formas de inserção dos indivíduos no mercado de trabalho.

Elaborado na década de 1950, o modelo de Lewis concebia o desenvolvimento econômico "como uma transição entre uma economia-sociedade tradicional (ou arcaica, ou rural) e uma economia-sociedade moderna (ou urbano-industrial)" (Ramos, 2007, p. 117). A abordagem dualista trazia em seu bojo a ideia de que haveria um fluxo de trabalhadores do setor arcaico rumo ao setor moderno, devido à atratividade dos melhores rendimentos do setor urbano-industrial. Esperava-se, assim, um transbordamento do desenvolvimento para uma parcela cada vez mais expressiva da população por meio da integração dos trabalhadores às atividades dinâmicas que financiariam a expansão capitalista (Furtado, 2004; Cacciamali, 2007).

De acordo com Mattos (1997), os "Anos Gloriosos" - período subsequente ao pós-Guerra ${ }^{1}$ - foram marcados pela consolidação, nos países centrais, de relações de trabalho mais estáveis, pela ampliação do nível global de emprego, por reduzidas taxas de desemprego, pela entrada da mulher no mercado de trabalho e pela melhoria dos perfis distributivos a partir da elevação dos salários reais. O autor destaca, ainda, a relevância da

$1 \bigcirc$ autor menciona que para a literatura anglo-saxônica esse período corresponde a aproximadamente vinte e cinco anos, enquanto os franceses o consideram como os "Trinta Gloriosos". 
expansão industrial na liderança do processo de crescimento econômico e expansão do emprego.

Vigorava no período em questão o que Chahad e Cacciamali (2005, p. 4) definem como paradigma do "direito ao emprego". Com seu ápice entre 1950 e 1970, o modelo típico das relações trabalhistas oriundas do desenvolvimento econômico era configurado por atributos como segurança de renda, proteção contra dispensa sem justa causa, direito ao trabalho e ao treinamento profissional, e o direito à saúde e segurança.

Entretanto, as experiências observadas pelos países subdesenvolvidos na modernização de suas atividades produtivas não permitiram a aceitação irrestrita das proposições vigentes. De acordo com Costa (2010), notou-se na América Latina e na África a não incorporação de segmentos produtivos e do mercado de trabalho ao ordenamento institucional de uma economia tipicamente capitalista e regulada. De acordo com a autora, esse fator motivou as discussões que precederam o conceito do "informal".

Nesse sentido, a produção acadêmica passou a buscar conceitos alternativos que caracterizassem de maneira mais realística as diferentes formas de ocupação dos indivíduos não incorporados aos setores tipicamente capitalistas. $\mathrm{O}$ artigo de Hart, elaborado em 1971 e publicado dois anos depois, por meio do qual a análise das atividades empreendidas pela população de Gana - que buscava aumentar seus rendimentos diante de um cenário de alto custo de vida, baixas remunerações e inacessibilidade à estrutura formal de oportunidades - dá origem ao campo de pesquisa sobre a informalidade. ${ }^{2}$

O caráter inovador do estudo consistiu em considerar empírica e teoricamente absurda a ideia de transição dos trabalhadores desempregados ou subempregados para o emprego em tempo integral por meio da mera conquista de um emprego no mercado de trabalho organizado (Hart, 1973, p. 83).

Hart queria demonstrar a possibilidade de as ocupações informais atuarem como um amortecedor para aqueles que não estavam inseridos em empregos regulares, na miséria ou na dependência de outros. Casos como o do pequeno comerciante de bebidas chamado Atinga, que intercalou vinte meses de desemprego, emprego formal e uma frágil atividade infor-

2 Outros conceitos - como a "economia de bazar", elaborado por Geertz em 1963, "circuitos inferior e superior", postulado por Milton Santos ao final da década de 1960, e "mercados formal e não formalizado", elaborado por Machado da Silva em 1971 - antecedem o artigo de Hart, porém sem o mesmo destaque e circulação do trabalho do antropólogo inglês. 
mal reforçavam a importância das atividades informais como uma alternativa viável para a sobrevivência de inúmeras famílias residentes na cidade (Hart, 1973, p. 79-81).

É importante mencionar que, ao contrário do que afirmam alguns críticos, Hart não defendia as atividades informais como um novo motor para o desenvolvimento, ou fazia uma apologia irrestrita à proliferação destas formas de ocupação. Isso fica claro na medida em que o autor argumentava que, para fins de subsistência, o emprego regular assalariado possuía algumas vantagens sólidas, ainda que com baixa remuneração, fazendo com que mesmo aqueles que auferiam rendas substanciais por meio de atividades informais podiam manter ou desejar o emprego formal (Hart, 1973, p. 78).

Mas em termos objetivos, de que forma o autor diferenciava as atividades formais das informais? Para Hart, esta distinção estava essencialmente baseada entre o assalariamento e o autoemprego, em que a variável chave consistia no grau de racionalidade do trabalho, se ele era - ou não - recrutado de forma permanente e regular por meio de remunerações fixas (Hart, 1973, p. 68). Assim, as oportunidades de renda formais derivavam dos salários do setor público, dos salários do setor privado e das transferências de pagamentos (pensões e seguro desemprego). Já as atividades que geravam rendas informais podiam ser legítimas - jardineiros, artesãos, pequenos comerciantes, vendedores ambulantes, músicos, barbeiros, fotógrafos, etc. - ou ilegítimas - contrabando, propina, prostituição, jogos de azar, etc. - (Hart, 1973, p. 69).

Outro importante aspecto abordado por Hart diz respeito às relações entre os setores formal e informal. Ao indicar que até então era entendido que o setor informal dependia da demanda criada pelos níveis da atividade no setor formal (total das despesas das remunerações formais), o autor questionava se os setores moviam-se em paralelo ou se havia a possibilidade de o nível de algumas atividades informais variarem inversamente às tendências formais. Sem se aprofundar no assunto, concluiu que a criação de demanda do setor informal dependia de um multiplicador de renda interno ao próprio setor, além das vendas para o setor formal, e que o saldo em conta corrente de pagamentos entre as economias formal e informal favorecia a primeira (Hart, 1973, p. 84-86).

Embora o próprio autor reconheça que o artigo carecia de uma visão geral das atividades urbanas informais em relação ao processo de subdesenvolvimento típico de Gana (Hart, 1973, p. 88), não se pode negligenciar a relevância do estudo de Hart para a economia do desenvolvimento e 
para o campo de pesquisa relativo à informalidade. Quatro décadas após a elaboração de seu artigo clássico, o próprio autor destaca que até o início da década de 1970 "a antítese à economia moderna conduzida pelo estado ainda não tinha encontrado seu nome acadêmico" (Hart, 2010, p. 145).

Então, o estudo de Hart possui um papel de vanguarda na medida em que confronta alguns pressupostos da literatura sobre desenvolvimento e propõe um novo campo de pesquisa - as atividades informais e seu potencial de geração de renda para os trabalhadores, geralmente em condições de pobreza. E, conforme indicado por Barbosa (2011, p. 108), tudo indica que o texto de Hart forneceu insumos para a missão de técnicos da OIT no Quênia, responsável pela elaboração de um relatório que credenciaria de vez o "setor informal" como uma temática de interesse de estudiosos e representantes de diversas instituições mundo afora.

Um dos aspectos de identificação entre o artigo de Hart e o relatório da missão Quênia (Employment, incomes andequality: a strategy for increasingproductiveemployment in Kenia) diz respeito à percepção de que o emprego formal não estaria disponível para todos os trabalhadores dos países em desenvolvimento. Para os técnicos da OIT, as vagas de trabalho do setor formal urbano eram insuficientes para atender àcrescente procura por empregos assalariados (ILO, 1972, p. 93). A explicação usual de que num processo de desenvolvimento econômico o setor moderno "ocidentalizado" seria a fonte de dinamismo e de mudança enquanto que o setor tradicional murcharia lentamente não correspondia à realidade do Quênia (ILO, 1972, p. 503).

Buscava-se avançar na construção conceitual que refletisse a realidade das atividades informais. Essas, para a OIT, não eram restritas às periferias, às ocupações específicas ou às atividades econômicas, mas encaradas como "a maneira de fazer as coisas" (ILO, 1972, p. 6). E, em termos práticos, possuíam as seguintes características: i) facilidade de entrada; ii) dependência de recursos locais; iii) propriedade familiar dos empreendimentos; iv) pequena escala de operação; v) intensiva em trabalho e utilização de tecnologia adaptada; vi) habilidades adquiridas fora do sistema de ensino formal; e vii) mercados desregulados e competitivos. Ademais, o relatório entendia o "formal" e o "informal" como uma terminologia meramente analítica alternativa à dualidade moderno-tradicional que traria preconceito contra o setor de baixos rendimentos (ILO, 1972, p. 503-504).

Se Hart adotara um tom cauteloso ao perceber as atividades informais como uma alternativa viável ao assalariamento e que não necessariamen- 
te deveriam ser caracterizadas como de baixa produtividade, o relatório Quênia era mais ousado. Em vários trechos do documento, os empreendimentos inseridos no setor informal eram tidos como lucrativos, eficientes, dinâmicos e criativos. Como ápice desse otimismo, destaca-se a visão do setor informal como "fonte de uma nova estratégia de desenvolvimento para o Quênia" (ILO, 1972, p. 505).

O relatório também admitia alguns aspectos negativos das atividades informais. Em comparação com as atividades formais, o setor informal apresentava níveis inferiores de status de trabalho, segurança e renda, além de trazer maior risco e incerteza aos que nele se inseriam. Além disso, as ocupações informais eram tidas como indesejáveis quando comparadas ao assalariamento formal (ILO, 1972, p. 7; 70; 224; 504).

É importante ressaltar que a exaltação do lado positivo e o reconhecimento dos aspectos negativos inerentes ao informal não se configuram necessariamente como uma contradição. Já se mencionou anteriormente que o relatório assumia o pressuposto de que o emprego formal não seria capaz de absorver o contingente populacional urbano em expansão, ou seja, ainda que incorporasse atividades indesejadas em termos comparativos, o setor informal representaria uma importante alternativa à ocupação e geração de renda no Quênia. Além disso, deve-se destacar que o relatório foi escrito por uma comissão ampla de acadêmicos - vinte e seis membros em tempo integral - que eventualmente poderia ter visões distintas (mais otimista ou mais comedida) sobre o fenômeno em questão.

Para os técnicos que compunham a missão da OIT no Quênia, a potencialidade do setor informal como indutor do desenvolvimento dependia da adoção de uma atitude positiva do governo no sentido de promovê-lo. Para tal, foram recomendadas algumas iniciativas pontuais relacionadas:

- à moradia - fim das demolições das casas dos informais;

- às licenças para funcionamento de negócios - revisão dos procedimentos, liberalização e desburocratização via eliminação de licenças desnecessárias;

- ao apoio técnico - pesquisa e desenvolvimento para uso na produção;

- à criação de vínculos com empresas maiores - promoção da subcontratação; e

- à utilização do poder de compras do governo - produtos e serviços contratados poderiam ser obtidos a partir de empresas do setor informal (ILO, 1972, p.22).

Independentemente da adesão dos governos a essas propostas, a visão 
de futuro da OIT era bem clara: "o setor informal nas áreas urbanas vai expandir-se nos próximos 20 anos" (ILO, 1972, p. 228). Na tentativa de elaborar um cenário prospectivo, o relatório julgava ser improvável uma redução do tamanho relativo do setor informal em virtude de uma elevação na taxa de participação do emprego no setor formal.

O alerta sobre a impossibilidade de observância do emprego formal em escala crescente nas economias em desenvolvimento talvez tenha sido um dos aspectos mais importantes do relatório da missão Quênia - e também do artigo de Hart. De acordo com Sethuraman (1976), a ideia de que seria necessário muito tempo para que os benefícios das políticas gerais de desenvolvimento chegassem aos mais pobres foi a principal razão para que fosse introduzido na literatura o termo "setor informal".

Para o autor, a nova dicotomia proposta (formal-informal) trazia duas novidades em relação à distinção moderno-tradicional: i) mudança de foco da análise sobre a economia urbana, que passaria a ser estudada a partir das características das empresas, e não dos indivíduos e dastecnologias utilizadas na produção; ii) neutralidade versus sentido pejorativo dado às atividades tradicionais (Sethuraman, 1976, p. 78-80).

Lacunas de cunho teórico-metodológico e excessos de otimismo quanto à importância do setor informal para o desenvolvimento dos países periféricos são limitações do relatório da OIT, mas, como ressalta Santos (1979) - também crítico à adoção do termo "setor informal" -, o fato de uma instituição multilateral importante decidir adotar uma palavra influencia a pesquisa oficial e os pesquisadores em geral.

Segundo Barbosa (2011), o documento deu respaldo ao setor informal como variável chave para que se entendesse o mundo do trabalho nos países periféricos. $\bigcirc$ autor enxerga como qualidade do relatório da missão Quênia a mistura de conceitos acadêmicos, proposições de políticas e pesquisa de campo, indicando que surgia uma nova trajetória de estudos que não tinha a pretensão de dominar as diferentes interpretações do fenômeno.

A divergência de fatores explicativos para a evolução do trabalho informal pode ser encarada como uma debilidade teórico-analítica, ou vista como um estímulo para pesquisas empíricas que avaliem o peso relativo dos diferentes tipos de informalidade, levando-se em conta que "todas as abordagens possuem ao menos um bom argumento no debate" (Noronha, 2003 , p. 120). Ao optar pelo segundo caminho, a próxima seção busca expor diferentes padrões de mensuração da informalidade. 


\section{Operacionalização do conceito: os diferentes modos de mensurar a informalidade}

Ao se deparar com questionamentos sobre a validade teórica do conceito "setor informal" e o fato do mesmo ser apreendido a partir de diferentes enfoques metodológicos, Hans Singer responde aos críticos utilizando-se de uma metáfora. Para o autor, a informalidade seria similar a uma girafa: todos a reconhecem facilmente, ainda que seja difícil descrevê-la (Cacciamali, 1982; Barbosa, 2011).

Vianna (2006) aponta quatro razões que dificultam a mensuração da informalidade: i) sua composição bastante heterogênea; ii) os limites entre trabalho e não-trabalho; iii) um leque de situações que estão no limite entre o formal e o informal; iv) qualidade dos instrumentos de pesquisa utilizados.

Cacciamali (1982) enumera pelo menos cinco formas de dimensionar o setor informal: i) trabalhadores desprotegidos pela legislação trabalhista; ii) atividades econômicas definidas a priori; iii) trabalhadores que não estão inseridos no setor formal; iv) firmas com um número mínimo de trabalhadores; ${ }^{3}$ vi) indivíduos (sejam empregadores, trabalhadores ou familiares) inseridos em empreendimentos de até quatro empregados, trabalhadores por conta própria (com exceção dos profissionais liberais), serviços domésticos e trabalhadores ocasionais.

Por sua vez, Vianna (2006) indica - com base no trabalho de Dagmar Raczynski- um conjunto de variáveis utilizado na caracterização e na estimativa do tamanho do setor informal na América Latina: i) ramo da atividade; ii) categoria ocupacional; iii) status migratório; iv) rendimento auferido; v) tipo de trabalho (fixo, flutuante ou ocasional); vi) quantidade de capital investida no empreendimento; vii) condições de trabalho; viii) posse de licenças - legalização do negócio; ix) forma de contabilidade (gestão); x) preço dos produtos/insumos; xi) tecnologia empregada na produção.

A numerosa produção de estudos e dados sobre o setor informal nos anos 1970 e 1980 se deu num contexto de ausência de recomendações amplamente aceitas sobre quais atividades deveriam ser classificadas como parte integrante do "setor formal" (Krein; Proni, 2010). Isso explica, em parte, a elevada diferenciação entre as estatísticas disponibilizadas por diferentes pesquisadores.

3 A autora indica que esse número mínimo utilizado como filtro mínimo para a formalidade varia entre 4 e 25 empregados. 
Contudo, no início dos anos 1990 percebe-se o empenho da OIT em estabelecer diretrizes para que os países passem a dispor de bases estatísticas adequadas sobre o emprego no setor informal. Como resultado da décima quinta Conferência Internacional de Estatísticos do Trabalho (CIET), foi elaborada uma resolução com orientações conceituais e metodológicas para que os países padronizassem a mensuração da informalidade. Entre os objetivos de tais recomendações, destaca-se a necessidade de os países produzirem estatísticas detalhadas sobre o número total de unidades do setor informal bem como o emprego total nessas unidades (ILO, 2000).

De maneira mais abrangente, o setor informal poderia ser descrito como "um conjunto de unidades que se dedicam à produção de bens ou à prestação de serviços com o objetivo principal de gerar emprego e renda para as pessoas envolvidas nesta atividade" (ILO, 2000, p. 2). Assim, o setor informal é definido e mensurado prioritariamente com base nas características das unidades produtivas (Hussmanns, 2004; Matsuo, 2009). Ademais, é composto por empreendimentos que funcionam em pequena escala, com pouca distinção entre trabalho e capital como fatores de produção, e em que predominam, ao invés de acordos contratuais com garantias formais, arranjos laborais baseados no parentesco e em relações pessoais (ILO, 2000).

Apesar das proposições elaboradas na décima quinta CIET indicarem que o limite mínimo de trabalhadores ocupados a ser utilizado como critério de identificação do setor informal deveria levar em conta circunstâncias nacionais, Hussmanns (2004) indica que existe uma recomendação do Delhi Groupon Informal Sector Statistics para que relatórios internacionais adotem o critério de menos de cinco empregados.

Mas, conforme exposto anteriormente, medir a informalidade exclusivamente a partir do recorte das unidades produtivas incorre em risco de reducionismo e compreensão parcial do fenômeno. Influenciada pelas ideias de Castells e Portes - abordagem neomarxista-institucionalista -, que propunham a revisão dos fundamentos conceituais da informalidade a partir da captura das novas configurações do mercado de trabalho, a OIT amplia seu escopo de análise sobre o "informal" (Barbosa, 2011).

$\mathrm{Na}$ Conferência Internacional do Trabalho de 2002, a instituição passa a perceber o termo "setor informal" como inadequado e até ilusório (misleading, no original), pois não reflete o caráter dinâmico, heterogê- 
neo e complexo inerente à informalidade, fenômeno que não se restringe à análise de um "setor" formado por grupos produtivos ou atividades econômicas específicas. A OIT sugere, então, que o termo "economia informal" seja utilizado como complemento ao conceito "setor informal" (ILO, 2002).

Em termos práticos, a OIT caracteriza a economia informal como "todas as atividades econômicas realizadas pelos trabalhadores e as unidades produtivas que - na lei e na prática - não estão cobertos ou que estão insuficientemente cobertos por sistemas formais" (Hussmanns, 2004, p. 2). Há uma diferenciação na variável chave que define os distintos conceitos: para a análise do "setor informal", a unidade de observação é o empreendimento produtivo, enquanto que o "emprego informal" se refere às características da ocupação individual (ILO, 2003).

As Diretrizes sobre uma definição estatística de emprego informal, adotadas na décima sétima CIET, traz à tona um novo marco conceitual sobre o emprego informal, ${ }^{4}$ baseado numa análise cruzada entre os tipos de unidades de produção (empresas do setor formal, empresas do setor informal e empresas familiares) e a posição na ocupação (trabalhadores por conta própria, empregadores, empregados assalariados, membros de cooperativas e trabalhadores familiares não remunerados).

Quadro 1 Marco conceitual: emprego informal

\begin{tabular}{|c|c|c|c|c|c|c|c|c|c|}
\hline \multirow{3}{*}{$\begin{array}{l}\text { Unidades } \\
\text { de produção } \\
\text { por tipo }\end{array}$} & \multicolumn{9}{|c|}{ Empregos por posição na ocupação } \\
\hline & \multicolumn{2}{|c|}{$\begin{array}{r}\text { Trabalhadores } \\
\text { por conta }\end{array}$} & \multicolumn{2}{|c|}{ Empregadores } & \multirow{2}{*}{$\begin{array}{r}\begin{array}{r}\text { Trabalhadores } \\
\text { familiares não- } \\
\text {-remunerados }\end{array} \\
\text { Informal }\end{array}$} & \multicolumn{2}{|c|}{$\begin{array}{l}\text { Empregados } \\
\text { assalariados }\end{array}$} & \multicolumn{2}{|c|}{$\begin{array}{l}\text { Membros de coopera- } \\
\text { tivas de produtores }\end{array}$} \\
\hline & Informal & Formal & Informal & Formal & & Informal & Formal & Informal & Formal \\
\hline $\begin{array}{l}\text { Empresas do } \\
\text { Setor Formal }\end{array}$ & & & & & 1 & 2 & & & \\
\hline $\begin{array}{l}\text { Empresas do } \\
\text { Setor Informal }\end{array}$ & 3 & & 4 & & 5 & 6 & 7 & 8 & \\
\hline $\begin{array}{l}\text { Empresas } \\
\text { familiares }\end{array}$ & 9 & & & & & 10 & & & \\
\hline
\end{tabular}

Fonte: ILO, 2003, p. 4.Tradução livre do autor.

4 "As células sombreadas em cinza escuro referem-se a postos de trabalho, que, por definição, não existem no tipo de unidade de produção em questão. As células sombreadas em cinza claro referem-se a empregos formais. Células não sombreadas representam os vários tipos de empregos informais" (ILO, 2003, p. 4, grifo do autor). 
Nesse quadro, o emprego informal está representado pelas células 1 a 6 e 8 a 10, o emprego no setor informal pelas células 3 a 8 , enquanto que o emprego informal fora do setor informal é exemplificado pelas células 1, 2, 9 e 10. De acordo com Hussmanns (2004), os conceitos são diferentes entre si e dizem respeito a aspectos distintos da informalização do emprego. Para o autor, ambos são úteis e se complementam.

Presume-se, portanto, a existência de situações em que o emprego informal pode ser observado em empresas que compõem o setor formal. Em contrapartida, alguns indivíduos ocupados como trabalhadores por conta própria - historicamente tidos como informais - podem estar vivenciando situações de emprego classificadas como formais do ponto de vista da cobertura social e da regulamentação das suas atividades junto às estruturas administrativas do Estado. ${ }^{5}$

O debate sobre os modos de mensuração da informalidade é mais amplo que o apresentado nesta seção e dificilmente se esgotará, dado que novas interpretações se combinarão às antigas formas de medir a participação de empreendimentos e indivíduos no universo laboral que rompe o paradigma do emprego regular.

Acredita-se, todavia, que o conteúdo apresentado até aqui confere maior consistência conceitual e metodológica para o estudo empírico proposto neste artigo. Se, na década de 1970, o trabalho por conta própria era intrinsecamente relacionado à informalidade, as recomendações estatísticas recentes sobre emprego informal consideram casos em que trabalhadores autônomos podem estar inseridos num emprego formal. É preciso, portanto, avançar na elaboração de análises sobre os subgrupos de ocupações específicas e entender o que explica a diferenciação entre indivíduos da mesma posição ocupacional no que tange à formalização de suas atividades e/ou empreendimentos. A próxima sessão busca contribuir com esse processo.

\section{Trabalho por conta própria no Brasil: uma análise re- cente sob o enfoque da heterogeneidade ocupacional}

Em 1958 a OIT, por meio da International Classification by Status Employment (ICSE), definiu o conceito "trabalhador por conta própria" como a pessoa 5 "Own-account workers and employers owning formal sector enterprises" (Hussmanns, 2004, p. 5). 
que opera o seu próprio empreendimento econômico, ou que se envolve de forma independente em uma profissão ou comércio, sem contratar funcionários. Se o conceito padronizado é relativamente novo, o fenômeno que ele captura remonta a tempos mais longínquos. De acordo com Hart (2010), economistas escoceses do século XVIII retrataram a ralé urbana de Glasgow e Edinburgh, enquanto os habitantes de favelas das cidades inglesas eram chamados de "a classe perigosa". Como exemplo de uma obra clássica que documenta a economia das ruas, o autor cita o livro London Labour and the Londor Poor, publicado por Mayhew nos anos 1860. Ressalta-se, nesse sentido, que "as pessoas tendem a esquecer que antes da criação das economias modernas [...] as atividades econômicas eram, em sua maioria, de caráter informal" (Tanzi, 2009, p. 37).

Ao longo do século XIX e boa parte do século XX, economistas e cientistas políticos acreditavam que o autoemprego estava fadado ao desaparecimento. Chahad e Cacciamali (2005) indicam que Karl Marx percebia esta categoria de trabalho como historicamente anacrônica, e que a produção capitalista tenderia a conquistar todos os espaços produtivos que até então eram ocupados por trabalhadores independentes. No mesmo sentido, Alfred Marshall acreditava que a eficiência e os ganhos de escala das grandes corporações implicariam diminuição do trabalho por conta própria e das pequenas empresas estabelecidas.

De certa forma, essa previsão fez sentido nos países que imprimiram um intenso processo de acumulação capitalista ao longo do século XX. Embasados em dados do estudo de Harry Braverman, Chahad e Cacciamali (2005) indicam que a proporção de trabalhadores por conta própria nos Estados Unidos caiu de quatro quintos da população (início do século XIX) para cerca de 10\% da população ocupada em 1970.

A tendência observada na sociedade norte-americana não se configura como regra para o conjunto das nações. De acordo com Prandi (1978), ainda que importantes teóricos tenham previsto o desaparecimento ou a redução do número de trabalhadores por conta própria, essa categoria sobreviveu e passou a ocupar as lacunas permitidas pelo modo de produção capitalista. Elaborada no fim da década de 1970, a obra $O$ trabalhador por conta própria sob o capital, de Reginaldo Prandi, é bastante útil para a compreensão da categoria ocupacional em questão. Trata, entre outros temas, da heterogeneidade inerente ao autoemprego. $\mathrm{O}$ autor indica que geralmente os trabalhadores por conta própria são prestadores de serviço 
que não dispõem de capital para gerir seus negócios nem de qualificação adequada para o trabalho formal, vivendo precariamente. Reconhece, entretanto, que também existem os casos "dos conta própria 'bem sucedidos economicamente' misturados às 'classes médias assalariadas' e que logram alcançar razoáveis condições de existência" (Prandi, 1978, p. 25). O autor defende, portanto, uma diferenciação dentre o conjunto de trabalhadores por conta própria (regulares versus irregulares), levando-se em consideração a grande variedade interna quanto à composição dos grupos ocupacionais.

Destaca-se, ainda, que o autor buscou, em sua análise, compreender a expansão do trabalho por conta própria no Brasil a partir de uma leitura histórica que incorporava desde a política de atração de imigrantes até a importância da urbanização para o crescimento da demanda por bens e serviços que ainda não tinham sido capturados pela produção capitalista. Não se pode desprezar o fato de que "o nascimento do mercado de trabalho ou, em outros termos, a ascensão do trabalho livre como base da economia, foi acompanhado pela entrada crescente de uma população trabalhadora no setor de subsistência e em atividades mal remuneradas" (Theodoro, 2005, p. 95).

Em outras palavras, no Brasil, o contingente de ex-escravos se junta aos trabalhadores nacionais livres nas áreas rurais em que se observam atividades de subsistência ou na periferia das cidades, ocupados em trabalhos temporários.

Houve, segundo Theodoro (2005), diferenças significativas no que diz respeito à formação dos mercados de trabalho regionais. Enquanto cidades como São Paulo e Rio de Janeiro dispunham de atividades industriais incipientes para imigrantes de origem italiana, portuguesa e espanhola, em Recife, o processo de urbanização teve como uma de suas principais características a ausência de oportunidades para a população livre após a abolição da escravatura. Essa combinação entre grande expansão demográfica e estagnação econômica teve como consequências "o subemprego e o desemprego, assim como a proliferação de "atividades informais'" (Theodoro, 2005, p. 108).

No mesmo sentido, Prandi (1978) argumenta que há uma relação inversa entre o patamar de desenvolvimento capitalista de uma região e o número de trabalhadores por conta própria que nela se inserem. O autor indica que entre os anos de 1940 e 1970 a participação dos trabalhadores 
por conta própria no total de ocupados teve um peso maior nas regiões Norte, Nordeste e Centro-Oeste, regiões menos desenvolvidas do país. Ou seja, "conforme cresce o PIB per capita, é esperada uma redução da participação do autoemprego na economia" (Gomes, 2009, p. 109).

Nesse período de trinta anos (1940-1970), os dados dos censos demográficos mostram que o percentual de trabalhadores por conta própria no total de ocupados (excetuando-se os setores agrícolas) cai de 36,4\% para 20,6\% (Prandi, 1978). Conforme veremos na próxima seção, essa proporção se mantém estável até o ano de 2014 - 21,3\% da população exerciam atividades inerentes ao trabalho por conta própria.

De acordo com Gomes (2009), esses dados indicam que a estruturação do mercado de trabalho assalariado no Brasil não se completou. Por sua vez, Holzmann (2013) interpreta que a significativa participação dos trabalhadores por conta própria no Brasil conduz à afirmação de que esta categoria ocupacional não é fortuita, mas sim um componente estrutural do mercado de trabalho do país.

O caráter contínuo do autoemprego no Brasil não elimina, entretanto, o debate sobre as flutuações do trabalho por conta própria e de outras formas de inserção dos indivíduos na estrutura ocupacional do país. Há certo consenso que na primeira década do século XXI o nível de informalidade se desacelerou devido, dentre outros fatores, à queda da participação de trabalhadores menos escolarizados e com baixa experiência de trabalho (Barbosa Filho; Moura, 2012). O panorama do trabalho brasileiro na última década é marcado pela

\footnotetext{
Redução das taxas médias de desemprego; expansão do emprego assalariado formal (protegido pela legislação trabalhista, social e previdenciária brasileira); crescimento do emprego nos setores mais organizados da economia (inclusive na grande empresa e no setor público); redução do peso do trabalho assalariado sem registro em carteira (ilegal) e do trabalho por conta própria na estrutura ocupacional; elevação substantiva do valor real do salário mínimo; recuperação do valor real dos salários negociados em convenções e acordos coletivos; importante redução do trabalho não remunerado; intensificação do combate ao trabalho forçado e redução expressiva do trabalho infantil. (Bartal et al., 2010, p. 10).
}

De acordo com os dados da Pesquisa Nacional por Amostra de Domicílios (PNAD), a proporção de trabalhadores com emprego assalariado no período 2001-2014 avançou de 54,3\% para 61,0\%, sendo que a parcela dos que possuem carteira assinada elevou-se de $29,4 \%$ para $39,1 \%$, enquanto aqueles sem carteira assinada tiveram perda de participação - 18,4\% em 2001; 14,7\% em 2014. 
Tabela 1 Pessoas de 10 anos ou mais ocupadas na semana de referência por posição na ocupação no trabalho principal - 2001 a 2014 - valores relativos (\%)

\begin{tabular}{|c|c|c|c|c|c|c|c|c|c|c|c|c|c|}
\hline $\begin{array}{l}\text { Posição na ocu- } \\
\text { pação no trabalho } \\
\text { principal }\end{array}$ & 2001 & 2002 & 2003 & 2004 & 2005 & 2006 & 2007 & 2008 & 2009 & 2011 & 2012 & 2013 & 2014 \\
\hline Total & 100,0 & 100,0 & 100,0 & 100,0 & 100,0 & 100,0 & 100,0 & 100,0 & 100,0 & 100,0 & 100,0 & 100,0 & 100,0 \\
\hline Empregados & 54,3 & 54,2 & 54,4 & 55,1 & 55,0 & 55,9 & 57,2 & 58,6 & 58,6 & 60,9 & 61,8 & 62,0 & 61,0 \\
\hline com carteira & 29,4 & 29,3 & 29,9 & 30,3 & 30,9 & 31,6 & 33,1 & 34,5 & 34,9 & 38,8 & 39,3 & 39,8 & 39,1 \\
\hline $\begin{array}{l}\text { Militares e } \\
\text { estatutários }\end{array}$ & 6,5 & 6,4 & 6,6 & 6,6 & 6,3 & 6,6 & 6,8 & 6,9 & 7,1 & 7,2 & 7,4 & 7,4 & 7,2 \\
\hline sem carteira & 18,4 & 18,5 & 17,9 & 18,3 & 17,8 & 17,7 & 17,3 & 17,2 & 16,5 & 15,0 & 15,1 & 14,7 & 14,7 \\
\hline $\begin{array}{l}\text { Trabalhadores } \\
\text { domésticos }\end{array}$ & 7,8 & 7,7 & 7,7 & 7,6 & 7,6 & 7,6 & 7,4 & 7,2 & 7,8 & 7,1 & 6,8 & 6,7 & 6,5 \\
\hline com carteira & 2,0 & 2,0 & 2,1 & 2,0 & 2,0 & 2,1 & 2,0 & 1,9 & 2,2 & 2,2 & 2,0 & 2,2 & 2,1 \\
\hline sem carteira & 5,8 & 5,8 & 5,6 & 5,7 & 5,6 & 5,5 & 5,4 & 5,2 & 5,6 & 4,9 & 4,8 & 4,5 & 4,5 \\
\hline Empregadores & 4,2 & 4,2 & 4,2 & 4,1 & 4,2 & 4,4 & 3,8 & 4,5 & 4,3 & 3,4 & 3,8 & 3,8 & 3,8 \\
\hline Conta própria & 22,3 & 22,3 & 22,4 & 22,0 & 21,6 & 21,2 & 21,2 & 20,2 & 20,5 & 21,0 & 20,6 & 20,6 & 21,3 \\
\hline $\begin{array}{l}\text { Construção para } \\
\text { uso próprio }\end{array}$ & 0,2 & 0,2 & 0,2 & 0,1 & 0,1 & 0,2 & 0,2 & 0,1 & 0,1 & 0,1 & 0,1 & 0,1 & 0,1 \\
\hline $\begin{array}{l}\text { Produção para } \\
\text { consumo próprio }\end{array}$ & 3,8 & 4,0 & 4,2 & 4,0 & 4,5 & 4,6 & 4,3 & 4,4 & 4,1 & 4,0 & 3,9 & 4,4 & 4,5 \\
\hline Não remunerados & 7,4 & 7,4 & 7,1 & 7,0 & 6,9 & 6,1 & 5,9 & 5,0 & 4,7 & 3,4 & 3,0 & 2,5 & 2,9 \\
\hline
\end{tabular}

Fonte: IBGE - Pesquisa Nacional por Amostra de Domicílios.

Apesar da redução, em termos proporcionais, do número de trabalhadores por conta própria nos anos 2000, analistas poderiam dizer que esta categoria contribui com $21,3 \%$ do total de ocupações informais do país. Entretanto, acredita-se que

Há uma tendência para superestimar o tamanho do setor informal pelo método tradicional. Uma parte significativa dos trabalhadores considerados informais na verdade é constituída de autônomos que contribuem para a Previdência elou possuem um número no CNPJ. (Corseuil; Reis, 2011, p. 30).

Os dados da PNAD 2014 indicam que do total de aproximadamente 21,2 milhões de trabalhadores por conta própria do país, $12,5 \%$ possuem o registro no CNPJ e, simultaneamente, contribuem para a previdência social. Outros $21,1 \%$ ou contribuem exclusivamente para a previdência $(14,6 \%)$ ou possuem somente o CNPJ (6,5\%). Ou seja, um terço $(33,6 \%)$ dos trabalhadores autônomos do Brasil se relacionam com instituições formais 
- previdência social - e/ou têm seus negócios registrados.

Calculando de outra forma, se considerássemos como critério para classificar o trabalhador como formal o fato deste contribuir para a previdência ou possuir o registro no CNPJ, o peso da categoria ocupacional no total de empregos informais cairia de $21,3 \%$ para $14,1 \%$, o que corrobora com a ideia de superestimação da informalidade junto aos trabalhadores autônomos, apresentada por Courseuil e Reis (2011).

A análise mais detalhada sobre as condições de informalidade junto aos trabalhadores por conta própria tem duas motivações. A primeira diz respeito ao fato da categoria ocupacional representar, para um conjunto de treze países da América Latina, o maior peso na composição do emprego informal da região $(41,6 \%) .{ }^{6}$ A segunda se refere à inquietação em possuir maior conhecimento sobre o potencial público-alvo de uma política inovadora adota pelo governo brasileiro para a formalização de trabalhadores autônomos.

O Estatuto Nacional da Microempresa e da Empresa de Pequeno Porte, promulgado em 2006, representa a iniciativa recente mais significativa no que diz respeito à promoção de uma "mudança da cultura da burocracia e da informalidade para a cultura da simplificação e da formalidade" (Sebrae, 2010). Contudo, ao passo que se iniciou a implementação desse novo arcabouço jurídico, percebeu-se que trabalhadores por conta própria não eram contemplados com incentivos mais efetivos para a formalização de seus negócios. Após a mobilização de diversos atores e entes governamentais, foi aprovada, em 2008, a Lei Complementar 128, que institui a figura jurídica do Microempreendedor Individual, representado pela "pessoa que trabalha por conta própria (trabalhador informal) e decide legalizar sua situação com o governo, tornando-se um pequeno empresário" (Câmara dos Deputados. Comissão de Desenvolvimento Econômico, Indústria e Comércio, 2010).

Após cinco anos de implementação da política - que efetivamente iniciou-se em julho de 2009 - 4.430 .764 pessoas aderiram ao programa (setembro de 2014, período em que a PNAD 2014 foi aplicada), de acordo com informações disponibilizadas pelo Portal do Empreendedor, ${ }^{7}$ sítio eletrônico por meio do qual qualquer trabalhador autônomo pode requerer o

6 Em segundo lugar aparecem os assalariados de empresas privadas, com 37,9\% da composição do emprego informal na América Latina, sendo que 27,5\% destes correspondem aos trabalhadores de empresas com até 10 funcionários (ILO, 2014).

7 Em fevereiro de 2016 já são 5.846.636 Microempreendedores Individuais formalizados, segundo o mesmo sítio. 
registro de Microempreendedor Individual (MEI). Entre os benefícios previstos $^{8}$ para aqueles que se formalizam, destacam-se:

- missão do registro no CNPJ - fazendo com que o trabalhador por conta própria possa ter acesso a linhas de crédito especiais e passe a emitir nota fiscal;

- isenção de taxas para o registro do negócio - o custo para permanecer formal é de $5 \%$ do valor de um salário mínimo (INSS) mais uma taxa de $\mathrm{R} \$ 5,00$ para prestadores de serviços ou $\mathrm{R} \$ 1,00$ para trabalhadores do comércio e da indústria;

- acesso a benefícios da Previdência Social - auxílio doença, aposentadoria por idade, salário-maternidade após carência, pensão e auxílio-reclusão; possibilidade de registrar até um (01) empregado a baixo custo ( $\mathrm{R}$ \$74,58 em junho de 2014);

- apoio técnico por meio de capacitações para a melhoria da gestão do negócio.

Courseuil, Neri e Ulyssea (2013) indicam a existência de um "efeito-formalização" após a implementação do programa do Microempreendedor Individual. Segundo os autores, há uma chance crescente, a partir de 2009, de um trabalhador por conta própria se formalizar. A necessidade de maior tempo de maturação da política para análise da mesma não impede a compreensão de que "esse processo de formalização propiciado pelo MEI deverá representar uma grande redução da informalidade do trabalho por conta própria, de empregadores e, portanto, do segmento dos pequenos negócios nos próximos anos no Brasil" (Santos, 2012).

O êxito da política está condicionado, entre outros fatores, a um conhecimento cada vez mais detalhado sobre o universo a qual os esforços devem ser concentrados: os trabalhadores por conta própria. Se compararmos o total de MEI formalizados no momento em que os pesquisadores da PNAD 2014 foram a campo - setembro de 2014 - com o total de trabalhadores por conta própria observa-se uma abrangência do programa em torno de $20 \%$ do total de trabalhadores por conta própria: 4,4 milhões de Microempreendedores Individuais diante do total de 21,2 milhões de trabalhadores por conta própria no país. Ainda que este cálculo tenha limitações pelo fato de que nem todo trabalhador autônomo se encaixa nas exigências para a formalização como MEI - limite de faturamento anual 8 Informações extraídas do Portal do Empreendedor: <http://www.portaldoempreendedor. gov.br/mei-microempreendedor-individual/beneficios $>$. 
de $\mathrm{R} \$ 60.000,00$ e tipo de atividade desempenhada -, percebe-se que há um espaço considerável para que uma proporção maior de trabalhadores por conta própria se formalize e possa usufruir dos benefícios previstos pela política.

É necessário, portanto, um conhecimento cada vez mais aprofundado sobre o heterogêneo público-alvo da política, que, como sugere o título deste artigo, engloba do catador (comércio de resíduos e sucatas) ao "doutor" - fisioterapeutas, dentistas, advogados, contadores.

\subsection{0 trabalho por conta própria no Brasil: análise exploratória de dados}

Estudos sobre o perfil do trabalhador por conta própria que levam em consideração a heterogeneidade da categoria ocupacional não representam uma novidade na produção acadêmica brasileira. Kon (2004) classifica os trabalhadores autônomos em três grupos: qualificados, semi-qualificados e não-qualificados. Galleazzi (2007), por sua vez, indica que o trabalho por conta própria pode ser desdobrado em sete categorias empíricas. $\bigcirc$ trabalho de Feijo, Do Nascimento e De Souza (2009) propõe a classificação das atividades que compõem o setor informal a partir de três níveis de informalidade: alta, média e baixa.

São escassas, entretanto, abordagens metodológicas que avancem na diferenciação entre os trabalhadores por conta própria que estão formalizados e aqueles que permanecem na situação de informalidade. $O$ trabalho de Corseuil e Reis (2011) pode ser considerado como pioneiro, ao adotar a análise exploratória para medir a probabilidade de um trabalhador por conta própria se formalizar como Microempreendedor Individual.

Esta seção trata-se de um estudo descritivo que fornece um retrato da atual configuração de informalidade entre os trabalhadores por conta própria no Brasil. Para tal, são utilizados dados da PNAD 2009 e PNAD 2014. Foram escolhidas quinze variáveis de análise, divididas em dois grupos: i) atributos sociodemográficos e ii) contexto laboral em que a atividade é no CNPJ para trabalhadores por conta própria, e os dados da PNAD 2014 são os mais recentes sobre o tema em questão - publicada em outubro de 2015. 
realizada. Alguns filtros foram efetuados, com o intuito de eliminar vieses de seleção. ${ }^{10}$ Indivíduos com menos de 25 anos e mais de 59 anos foram excluídos, tendo em vista que estão em ciclos de vida específicos que condicionam sua situação ocupacional: "a taxa de participação dos indivíduos mais jovens no trabalho por conta própria é bem inferior à taxa verificada no total de empregados" (Gomes, 2009, p. 90). Além disso, foram considerados somente os trabalhadores por conta própria das áreas urbanas, levando-se em consideração o fato de que os estudos teóricos e empíricos comumente adotam esse recorte.

Tabela 2 Caracterização da informalidade dos trabalhadores por conta própria no Brasil urbano e adulto - variáveis sociodemográficas - 2009/2014

\begin{tabular}{|c|c|c|c|c|c|c|c|c|c|c|}
\hline & \multicolumn{5}{|r|}{2009} & \multicolumn{5}{|r|}{2014} \\
\hline & Total & INF & CP & CNPJ & PREV+CNPJ & Total & INF & CP & CNPJ & PREV+CNPJ \\
\hline \multicolumn{11}{|l|}{ Sexo } \\
\hline Masculino & 7.286 .799 & $68,4 \%$ & $13,8 \%$ & $9,3 \%$ & $8,4 \%$ & 8.527 .264 & $61,0 \%$ & $16,1 \%$ & $7,1 \%$ & $15,8 \%$ \\
\hline Feminino & 4.427 .105 & $73,9 \%$ & $10,5 \%$ & $8,5 \%$ & $7,1 \%$ & 4.772 .736 & $60,0 \%$ & $15,6 \%$ & $7,7 \%$ & $16,6 \%$ \\
\hline \multicolumn{11}{|l|}{ Cor / Raça } \\
\hline Indigena & 33.582 & $82,7 \%$ & $9,3 \%$ & $4,3 \%$ & $3,7 \%$ & 41.854 & $68,1 \%$ & $13,1 \%$ & $9,2 \%$ & $9,6 \%$ \\
\hline Branca & 5.731 .421 & $60,1 \%$ & $16,3 \%$ & $11,1 \%$ & $12,5 \%$ & 6.048 .881 & $49,6 \%$ & $19,1 \%$ & $9,0 \%$ & $22,4 \%$ \\
\hline Preta & 884.499 & $80,1 \%$ & $10,2 \%$ & $7,2 \%$ & $2,5 \%$ & 1.275 .553 & $68,7 \%$ & $14,9 \%$ & $6,4 \%$ & $9,9 \%$ \\
\hline Amarela & 57.833 & $44,6 \%$ & $16,3 \%$ & $15,7 \%$ & $23,3 \%$ & 64.371 & $27,8 \%$ & $19,7 \%$ & $17,2 \%$ & $35,4 \%$ \\
\hline Parda & 5.006 .569 & $80,8 \%$ & $8,7 \%$ & $7,0 \%$ & $3,6 \%$ & 5.869 .341 & $70,6 \%$ & $12,9 \%$ & $5,7 \%$ & $10,9 \%$ \\
\hline \multicolumn{11}{|l|}{ Faixa Etária } \\
\hline 25 a 29 anos & 1.344 .365 & $76,8 \%$ & $7,3 \%$ & $9,4 \%$ & $6,6 \%$ & 1.420 .852 & $67,3 \%$ & $8,4 \%$ & $8,6 \%$ & $15,7 \%$ \\
\hline 30 a 34 anos & 1.700 .782 & $73,3 \%$ & $8,5 \%$ & $10,4 \%$ & $7,8 \%$ & 1.948 .751 & $62,5 \%$ & $11,4 \%$ & $8,8 \%$ & $17,3 \%$ \\
\hline 35 a 39 anos & 1.802 .670 & $72,6 \%$ & $10,4 \%$ & $9,3 \%$ & $7,7 \%$ & 2.059 .901 & $62,0 \%$ & $13,3 \%$ & $7,9 \%$ & $16,8 \%$ \\
\hline $40 \mathrm{a} 44$ anos & 1.970 .349 & $71,0 \%$ & $12,4 \%$ & $9,0 \%$ & $7,6 \%$ & 2.096 .932 & $61,7 \%$ & $16,0 \%$ & $5,6 \%$ & $16,6 \%$ \\
\hline 45 a 49 anos & 1.878 .496 & $67,4 \%$ & $15,0 \%$ & $9,0 \%$ & $8,5 \%$ & 2.109 .335 & $57,9 \%$ & $18,9 \%$ & $7,4 \%$ & $15,8 \%$ \\
\hline 50 a 54 anos & 1.710 .963 & $66,4 \%$ & $17,3 \%$ & $7,5 \%$ & $8,8 \%$ & 2.013 .631 & $57,3 \%$ & $20,0 \%$ & $6,2 \%$ & $16,4 \%$ \\
\hline 55 a 59 anos & 1.306 .279 & $65,9 \%$ & $17,0 \%$ & $8,6 \%$ & $8,4 \%$ & 1.650 .598 & $57,1 \%$ & $22,3 \%$ & $6,9 \%$ & $13,7 \%$ \\
\hline \multicolumn{11}{|c|}{ Região de residência } \\
\hline Norte & 946.234 & $86,4 \%$ & $3,9 \%$ & $7,5 \%$ & $2,2 \%$ & 1.162 .089 & $82,3 \%$ & $5,5 \%$ & $5,4 \%$ & $6,8 \%$ \\
\hline Nordeste & 3.149 .083 & $85,7 \%$ & $6,7 \%$ & $5,1 \%$ & $2,5 \%$ & 3.480 .292 & $76,1 \%$ & $10,1 \%$ & $5,3 \%$ & $8,5 \%$ \\
\hline Sudeste & 5.111 .806 & $62,9 \%$ & $17,1 \%$ & $10,0 \%$ & $10,0 \%$ & 5.818 .773 & $51,8 \%$ & $20,6 \%$ & $8,2 \%$ & $19,4 \%$ \\
\hline
\end{tabular}

10 Com tais filtros, o universo de análise é reduzido de 21,2 milhões para 13,3 milhões de trabalhadores por conta própria. 


\begin{tabular}{|c|c|c|c|c|c|c|c|c|c|c|}
\hline & \multicolumn{5}{|r|}{2009} & \multicolumn{5}{|r|}{2014} \\
\hline & Total & INF & CP & CNPJ & PREV+CNPJ & Total & INF & CP & CNPJ & PREV+CNPJ \\
\hline Sul & 1.592 .182 & $53,4 \%$ & $16,1 \%$ & $14,2 \%$ & $16,4 \%$ & 1.752 .885 & $44,6 \%$ & $21,2 \%$ & $7,8 \%$ & $26,3 \%$ \\
\hline Centro-Oeste & 914.599 & $73,5 \%$ & $10,3 \%$ & $9,8 \%$ & $6,4 \%$ & 1.085 .961 & $60,8 \%$ & $12,4 \%$ & $10,2 \%$ & $16,7 \%$ \\
\hline \multicolumn{11}{|l|}{ Anos de estudo } \\
\hline $\begin{array}{l}\text { Sem instrução e } \\
\text { menos de } 1 \text { ano }\end{array}$ & 823.079 & $87,9 \%$ & $7,1 \%$ & $4,3 \%$ & $0,7 \%$ & 833.199 & $83,0 \%$ & $10,2 \%$ & $2,8 \%$ & $4,0 \%$ \\
\hline 1a 3 anos & 1.177 .251 & $85,3 \%$ & $7,3 \%$ & $5,0 \%$ & $2,4 \%$ & 950.042 & $79,0 \%$ & $12,4 \%$ & $2,5 \%$ & $6,1 \%$ \\
\hline 4 a 7 anos & 3.316 .747 & $77,7 \%$ & $11,8 \%$ & $6,1 \%$ & $4,3 \%$ & 3.158 .273 & $69,8 \%$ & $16,0 \%$ & $4,7 \%$ & $9,5 \%$ \\
\hline $8 \mathrm{a} 10$ anos & 2.088.036 & $72,7 \%$ & $12,2 \%$ & $8,9 \%$ & $6,1 \%$ & 2.412 .784 & $63,8 \%$ & $15,1 \%$ & $7,8 \%$ & $13,3 \%$ \\
\hline 11 a 14 anos & 3.281 .939 & $63,4 \%$ & $14,4 \%$ & $11,4 \%$ & $10,8 \%$ & 4.449 .796 & $54,0 \%$ & $16,6 \%$ & $8,7 \%$ & $20,7 \%$ \\
\hline 15 anos ou mais & 1.006 .723 & $32,7 \%$ & $20,6 \%$ & $19,8 \%$ & $26,9 \%$ & 1.482 .828 & $31,3 \%$ & $20,8 \%$ & $13,5 \%$ & $34,4 \%$ \\
\hline Não determinados & 20.129 & $87,5 \%$ & $7,9 \%$ & $3,0 \%$ & $1,6 \%$ & 13.078 & $86,0 \%$ & $6,4 \%$ & $0,0 \%$ & $7,6 \%$ \\
\hline \multicolumn{11}{|l|}{ Código da área censitária } \\
\hline Região metropolitana & 4.136.399 & $66,7 \%$ & $13,1 \%$ & $11,1 \%$ & $9,2 \%$ & 4.557 .432 & $56,6 \%$ & $17,3 \%$ & $8,8 \%$ & $17,4 \%$ \\
\hline Autorrepresentativo & 3.038 .449 & $69,1 \%$ & $12,9 \%$ & $9,5 \%$ & $8,5 \%$ & 3.878 .133 & $59,9 \%$ & $16,5 \%$ & $7,5 \%$ & $16,2 \%$ \\
\hline Não autorrepresentativo & 4.539 .056 & $74,8 \%$ & $11,9 \%$ & $6,9 \%$ & $6,4 \%$ & 4.864 .435 & $65,1 \%$ & $14,3 \%$ & $5,8 \%$ & $14,9 \%$ \\
\hline \multicolumn{11}{|c|}{ Utilização internet (últimos 3 meses) } \\
\hline Sim & 3.922 .672 & $53,4 \%$ & $16,0 \%$ & $14,5 \%$ & $16,2 \%$ & 7.185 .839 & $49,3 \%$ & $17,2 \%$ & $9,8 \%$ & $23,6 \%$ \\
\hline Não & 7.791 .232 & $79,1 \%$ & $10,9 \%$ & $6,3 \%$ & $3,8 \%$ & 6.114 .161 & $73,9 \%$ & $14,4 \%$ & $4,4 \%$ & $7,3 \%$ \\
\hline
\end{tabular}

Fonte: IBGE - Pesquisa Nacional por Amostra de Domicílios - 2009 e 2014. Elaboração do autor.

INF = Informal / CP = Contribuição Previdenciária / CNPJ - registro no CNPJ / PREV+CNPJ = Contribuição Previdenciária e Registro no CNPJ.

De uma maneira geral, o trabalhador por conta própria no Brasil é do sexo masculino $(64,1 \%)$, da cor branca $(45,5 \%)$ ou parda $(44,1 \%)$, situa-se na faixa entre 40 e 49 anos $(31,6 \%)$, reside no Sudeste (43,8\%) ou no Nordeste $(26,2 \%)$, em municípios fora das regiões metropolitanas $(65,7 \%)$, tem menos de 7 anos (37,2\%) ou entre 11 e 14 anos de estudo (33,5\%), e utilizou a internet nos últimos 3 meses $\left(54,0 \%{ }^{11}\right)$.

De acordo com o exposto na Tabela 2 , há um equilíbrio entre o grau de formalização entre homens e mulheres, todavia destaca-se que a redução da informalidade entre as mulheres no período 2009-2014 deu-se de forma mais intensa $(13,8 \%)$ comparativamente à observada entre os autônomos do sexo masculino $(7,4 \%)$.

11 Elevação significativa em comparação com 2009, quando apenas 33,5\% dos trabalhadores por conta própria haviam utilizado internet recentemente (últimos 3 meses). 
O mesmo não pode ser dito com relação à variável raça/cor da pele. Ainda que a taxa de informalidade entre os negros tenha sofrido redução levemente mais expressiva do que a observada entre os brancos $(11,3 \%$ e 10,5\%, respectivamente), ainda há uma diferença significativa na informalidade entre trabalhadores por conta própria negros (68,7\%) e brancos (49,6\%). Para Theodoro (2005), a exclusão e escassez de oportunidades no Brasil tocam particularmente os negros e mulatos, ainda como resquícios das condições às quais eram submetidos durante e após a escravidão.

Com relação à idade do trabalhador por conta própria, percebe-se uma tendência de redução no grau de informalidade à medida que o indivíduo se torna mais velho. $\bigcirc$ mesmo não ocorre quando se observa o grau de escolaridade. Indivíduos com mais anos de estudo apresentam um percentual de informalidade mais baixo em relação àqueles com pouca instrução. No período 2009-2014, a redução do nível de informalidade foi mais significativa no grupo de trabalhadores com 11 a 14 anos de estudo $(9,4 \%)$ do que no grupo de trabalhadores sem instrução e menos de 1 ano de estudo $(4,9 \%)$ ou com 1 a 3 anos de estudo (6,3\%).

Neste sentido, ressalta-se a pertinência da proposta de Arbache (2003). O autor defende a implantação de projetos de alfabetização e escolarização dos indivíduos inseridos em situação de informalidade como meio de fortalecimento de seus negócios.

A forma como o indivíduo se relaciona com o mercado de trabalho a partir da realização de sua atividade econômica também é analisada nesta seção. Quatro em cada dez trabalhadores por conta própria (44,0\%) desempenham sua atividade há menos de cinco anos, enquanto cerca de um terço $(34,9 \%)$ está inserido nessa categoria ocupacional há mais de 10 anos. Ou seja, ainda que haja rotatividade - entrada e saída de inúmeros indivíduos em tal categoria ocupacional -, o trabalho autônomo não possui um caráter eventual na sociedade brasileira, configurando-se, assim, um processo estrutural (Holzmann, 2013).

Nos últimos cinco anos (2009-2014), a redução da informalidade foi mais acentuada no grupo de profissionais com 1 a 5 anos de experiência no trabalho por conta própria - queda de $11,1 \%$ contra $7,3 \%$ dos trabalhadores que atuam há mais de 20 anos. A estratégia de reforçar a formalização dos autônomos com menos tempo de trabalho pode gerar ampliação da cobertura previdenciária e acesso a serviços de assistência técnica aos empreendimentos (registrados no CNPJ). 
Tabela 3 Caracterização da informalidade dos trabalhadores por conta própria no Brasil urbano e adulto - variáveis relacionadas ao trabalho - 2009/2014 - parte 1

\begin{tabular}{|c|c|c|c|c|c|c|c|c|c|c|}
\hline & \multicolumn{5}{|r|}{2009} & \multicolumn{5}{|r|}{2014} \\
\hline & Total & INF & CP & CNPJ & PREV+CNPJ & Total & INF & CP & CNPJ & PREV+CNPJ \\
\hline \multicolumn{11}{|l|}{ Tempo de trabalho } \\
\hline Menos de 1 ano & 1.184 .793 & $77,3 \%$ & $6,2 \%$ & $12,2 \%$ & $4,3 \%$ & 1.071 .628 & $72,5 \%$ & $8,1 \%$ & $9,1 \%$ & $10,3 \%$ \\
\hline 1a 5 anos & 4.089.837 & $73,2 \%$ & $9,1 \%$ & $9,9 \%$ & $7,7 \%$ & 4.777 .643 & $62,1 \%$ & $13,1 \%$ & $8,1 \%$ & $16,8 \%$ \\
\hline 6 a 10 anos & 2.529 .969 & $69,5 \%$ & $13,5 \%$ & $8,5 \%$ & $8,5 \%$ & 2.804 .823 & $58,8 \%$ & $16,8 \%$ & $7,2 \%$ & $17,1 \%$ \\
\hline 11 a 15 anos & 1.450 .804 & $67,6 \%$ & $15,0 \%$ & $8,7 \%$ & $8,7 \%$ & 1.490 .202 & $58,0 \%$ & $17,7 \%$ & $6,8 \%$ & $17,5 \%$ \\
\hline 16 a 20 anos & 1.183 .430 & $65,7 \%$ & $16,5 \%$ & $7,4 \%$ & $10,4 \%$ & 1.480 .116 & $56,9 \%$ & $19,8 \%$ & $6,2 \%$ & $17,0 \%$ \\
\hline Mais de 20 anos & 1.275 .071 & $65,0 \%$ & $21,4 \%$ & $6,1 \%$ & $7,6 \%$ & 1.675 .588 & $57,6 \%$ & $22,7 \%$ & $5,4 \%$ & $14,2 \%$ \\
\hline \multicolumn{11}{|c|}{ Procurou trabalho na semana de referência } \\
\hline $\operatorname{Sim}$ & 1.631 .051 & $83,5 \%$ & $6,7 \%$ & $7,2 \%$ & $2,7 \%$ & 1.188 .547 & $77,2 \%$ & $11,3 \%$ & $5,9 \%$ & $5,6 \%$ \\
\hline Não & 10.082 .853 & $68,3 \%$ & $13,5 \%$ & $9,3 \%$ & $8,8 \%$ & 12.111.453 & $59,0 \%$ & $16,4 \%$ & $7,4 \%$ & $17,2 \%$ \\
\hline \multicolumn{11}{|c|}{ Faixa de rendimento mensal per capita - SM = salário mínimo } \\
\hline Até $1 / 4$ SM & 724.879 & $93,9 \%$ & $3,0 \%$ & $2,8 \%$ & $0,2 \%$ & 558.901 & $89,6 \%$ & $6,4 \%$ & $2,5 \%$ & $1,5 \%$ \\
\hline Mais de $1 / 4$ até $1 / 2$ SM & 1.708 .590 & $89,7 \%$ & $5,6 \%$ & $3,8 \%$ & $0,9 \%$ & 1.585 .651 & $83,7 \%$ & $9,4 \%$ & $3,0 \%$ & $3,9 \%$ \\
\hline Mais de $1 / 2$ até 1 SM & 3.197 .927 & $80,8 \%$ & $9,6 \%$ & $6,7 \%$ & $2,9 \%$ & 3.428 .947 & $73,3 \%$ & $13,8 \%$ & $4,8 \%$ & $8,1 \%$ \\
\hline Mais de 1 até 2 SM & 3.137.477 & $65,8 \%$ & $15,5 \%$ & $10,1 \%$ & $8,6 \%$ & 3.999 .501 & $56,1 \%$ & $18,5 \%$ & $7,5 \%$ & $17,9 \%$ \\
\hline Mais de 2 até 3 SM & 1.110 .964 & $52,8 \%$ & $18,1 \%$ & $13,7 \%$ & $15,4 \%$ & 1.514 .701 & $41,6 \%$ & $21,7 \%$ & $10,0 \%$ & $26,7 \%$ \\
\hline Mais de 3 até 5 SM & 758.608 & $42,5 \%$ & $22,3 \%$ & $14,7 \%$ & $20,6 \%$ & 897.190 & $34,3 \%$ & $18,5 \%$ & $14,0 \%$ & $33,3 \%$ \\
\hline Mais de 5 SM & 543.734 & $27,2 \%$ & $22,1 \%$ & $20,3 \%$ & $30,4 \%$ & 662.700 & $26,0 \%$ & $18,0 \%$ & $15,2 \%$ & $40,9 \%$ \\
\hline Sem declaração & 511.492 & $62,1 \%$ & $14,0 \%$ & $12,9 \%$ & $11,0 \%$ & 633.286 & $56,5 \%$ & $16,1 \%$ & $11,1 \%$ & $16,3 \%$ \\
\hline \multicolumn{11}{|l|}{ Sócio ocupado } \\
\hline Sim & 1.298 .838 & $47,6 \%$ & $12,3 \%$ & $16,0 \%$ & $24,1 \%$ & 1.367 .927 & $36,1 \%$ & $9,4 \%$ & $16,1 \%$ & $38,3 \%$ \\
\hline Não & 9.751 .090 & $72,8 \%$ & $12,4 \%$ & $8,5 \%$ & $6,3 \%$ & 11.202 .897 & $62,9 \%$ & $16,5 \%$ & $6,5 \%$ & $14,2 \%$ \\
\hline \multicolumn{11}{|c|}{ Ocupou alguém não remunerado } \\
\hline Sim & 1.043 .817 & $65,3 \%$ & $10,5 \%$ & $12,0 \%$ & $12,2 \%$ & 942.960 & $52,1 \%$ & $11,4 \%$ & $10,8 \%$ & $25,7 \%$ \\
\hline Não & 10.670 .087 & $71,0 \%$ & $12,8 \%$ & $8,7 \%$ & $7,5 \%$ & 12.357 .040 & $61,3 \%$ & $16,3 \%$ & $7,0 \%$ & $15,4 \%$ \\
\hline
\end{tabular}

Fonte: IBGE - Pesquisa Nacional por Amostra de Domicílios - 2009 e 2014. Elaboração do autor.

Com relação a uma possível saída da categoria ocupacional, percebe-se que um número restrito de trabalhadores por conta própria procurou outro trabalho na semana de referência (8,9\%), sendo que,desses, 80,8\% eram informais. Ou seja, de modo geral os indivíduos ou estão satisfeitos com a sua ocupação ou não consideram ser viável inserir-se num emprego assa- 
lariado. ${ }^{12}$ Corrobora esta tendência o fato do percentual dos trabalhadores por conta própria que procuraram trabalho em 2014 ter apresentado uma queda em relação ao patamar observado em 2009 (13,9\%).

Sete em cada dez trabalhadores por conta própria $(72,1 \%)$ residem em domicílios com o rendimento per capita inferior a dois salários mínimos. Destaca-se, como era de esperar, que na medida em que os rendimentos se tornam maiores há uma diminuição da proporção de indivíduos que nem contribuem para a previdência nem possuem registro no CNPJ. Considerando-se a evolução temporal 2009-2014, fica evidente a necessidade de formalização dos trabalhadores autônomos com menor rendimento familiar per capita - o grupo que observou maior redução na informalidade foi o de autônomos com dois a três salários mínimos (queda de 11,1\%). Em contrapartida, no grupo de trabalhadores com renda per capita inferior a $1 / 4$ de salário mínimo ou entre $1 / 4$ e $1 / 2$ do salário mínimo, observou-se redução da informalidade na ordem de $4,3 \%$ e $6,0 \%$, respectivamente.

Tabela 4 Caracterização da informalidade dos trabalhadores por conta própria no Brasil urbano e adulto - variáveis relacionadas ao trabalho - 2009/2014 - parte 2

\begin{tabular}{|c|c|c|c|c|c|c|c|c|c|c|}
\hline & \multicolumn{5}{|r|}{2009} & \multicolumn{5}{|r|}{2014} \\
\hline & Total & INF & CP & CNPJ & PREV+CNPJ & Total & INF & CP & CNPJ & PREV+CNP] \\
\hline \multicolumn{11}{|l|}{ Tipo de estabelecimento } \\
\hline $\begin{array}{l}\text { Loja, oficina, fábrica, es- } \\
\text { critório, escola, repartiç̧ão } \\
\text { pública, galpão, etc. }\end{array}$ & 3.192 .316 & $44,5 \%$ & $14,0 \%$ & $19,5 \%$ & $22,0 \%$ & 4.194 .387 & $36,1 \%$ & $14,2 \%$ & $14,9 \%$ & $34,7 \%$ \\
\hline $\begin{array}{l}\text { Fazenda, sitio, granja, } \\
\text { chácara, etc. }\end{array}$ & 541.915 & $84,4 \%$ & $11,2 \%$ & $3,4 \%$ & $1,0 \%$ & 631.713 & $76,4 \%$ & $14,4 \%$ & $4,1 \%$ & $5,1 \%$ \\
\hline $\begin{array}{l}\text { No domicilio em } \\
\text { que morava }\end{array}$ & 2.656 .428 & $79,9 \%$ & $9,9 \%$ & $6,7 \%$ & $3,5 \%$ & 2.653 .088 & $69,3 \%$ & $14,8 \%$ & $5,0 \%$ & $10,9 \%$ \\
\hline $\begin{array}{l}\text { Em domicilio de } \\
\text { empregador, patrão, sócio } \\
\text { ou freguês }\end{array}$ & 852.694 & $85,6 \%$ & $9,1 \%$ & $4,1 \%$ & $1,2 \%$ & 287.526 & $71,6 \%$ & $16,0 \%$ & $4,3 \%$ & $8,2 \%$ \\
\hline $\begin{array}{l}\text { Em local designado pelo } \\
\text { empregador, cliente ou } \\
\text { freguês }\end{array}$ & 2.696 .234 & $81,0 \%$ & $11,9 \%$ & $4,6 \%$ & $2,5 \%$ & 3.761 .263 & $75,2 \%$ & $15,8 \%$ & $3,3 \%$ & $5,7 \%$ \\
\hline Em veículo automotor & 678.287 & $60,2 \%$ & $27,2 \%$ & $6,3 \%$ & $6,3 \%$ & 821.759 & $56,4 \%$ & $30,0 \%$ & $3,5 \%$ & $10,1 \%$ \\
\hline
\end{tabular}

12 De acordo com Curi e Menezes Filho (2006), apenas 7,4\% dos indivíduos inseridos no ano 2000 em empregos assalariados do setor formal tinham como origem (1992) o trabalho por conta própria. 


\begin{tabular}{|c|c|c|c|c|c|c|c|c|c|c|}
\hline & \multicolumn{5}{|r|}{2009} & \multicolumn{5}{|r|}{2014} \\
\hline & Total & INF & CP & CNPJ & PREV+CNPJ & Total & INF & CP & CNPJ & PREV+CNPJ \\
\hline Em via ou área pública & 983.747 & $86,0 \%$ & $9,6 \%$ & $3,4 \%$ & $1,0 \%$ & 890.332 & $78,2 \%$ & $14,6 \%$ & $2,4 \%$ & $4,8 \%$ \\
\hline Outro & 112.283 & $75,0 \%$ & $21,6 \%$ & $2,5 \%$ & $0,9 \%$ & 59.932 & $61,3 \%$ & $38,7 \%$ & $0,0 \%$ & $0,0 \%$ \\
\hline \multicolumn{11}{|c|}{ Grupos de ocupação de trabalho } \\
\hline Agrícola & 741.971 & $81,5 \%$ & $14,9 \%$ & $3,0 \%$ & $0,7 \%$ & 820.786 & $72,6 \%$ & $19,2 \%$ & $3,4 \%$ & $4,8 \%$ \\
\hline $\begin{array}{l}\text { Outras atividades } \\
\text { industriais }\end{array}$ & 6.942 & $91,7 \%$ & $3,2 \%$ & $0,0 \%$ & $5,2 \%$ & 17.760 & $91,5 \%$ & $6,7 \%$ & $0,0 \%$ & $1,8 \%$ \\
\hline $\begin{array}{l}\text { Indústria de transfor- } \\
\text { mação }\end{array}$ & 1.596 .453 & $78,2 \%$ & $10,8 \%$ & $6,9 \%$ & $4,1 \%$ & 1.396 .654 & $66,0 \%$ & $15,4 \%$ & $5,2 \%$ & $13,5 \%$ \\
\hline Construçãa & 2.082 .433 & $84,6 \%$ & $11,1 \%$ & $3,0 \%$ & $1,3 \%$ & 2.848 .983 & $76,1 \%$ & $15,8 \%$ & $2,9 \%$ & $5,1 \%$ \\
\hline Comércio e reparação & 3.261 .111 & $67,7 \%$ & $9,7 \%$ & $11,7 \%$ & $11,0 \%$ & 3.407 .919 & $54,5 \%$ & $11,1 \%$ & $10,3 \%$ & $24,2 \%$ \\
\hline Alojamento e alimentação & 670.255 & $66,7 \%$ & $9,0 \%$ & $13,6 \%$ & $10,7 \%$ & 829.072 & $62,4 \%$ & $11,1 \%$ & $9,8 \%$ & $16,8 \%$ \\
\hline $\begin{array}{l}\text { Transporte, armazenagem } \\
\text { e comunicação }\end{array}$ & 913.504 & $61,5 \%$ & $23,1 \%$ & $7,6 \%$ & $7,8 \%$ & 1.038 .165 & $56,4 \%$ & $25,9 \%$ & $5,2 \%$ & $12,6 \%$ \\
\hline $\begin{array}{l}\text { Educação, saúde e } \\
\text { serviços sociais }\end{array}$ & 338.336 & $46,4 \%$ & $20,8 \%$ & $14,1 \%$ & $18,6 \%$ & 428.289 & $38,0 \%$ & $27,6 \%$ & $8,1 \%$ & $26,2 \%$ \\
\hline $\begin{array}{l}\text { Outros serviços coletivos, } \\
\text { sociais e pessoais }\end{array}$ & 1.112 .754 & $72,6 \%$ & $12,7 \%$ & $9,2 \%$ & $5,4 \%$ & 1.458 .541 & $57,4 \%$ & $16,5 \%$ & $8,7 \%$ & $17,4 \%$ \\
\hline Outras atividades & 882.598 & $39,3 \%$ & $17,9 \%$ & $19,3 \%$ & $23,5 \%$ & 1.029 .350 & $36,9 \%$ & $19,3 \%$ & $13,6 \%$ & $30,1 \%$ \\
\hline Atividades mal definidas & 107.547 & $96,3 \%$ & $1,3 \%$ & $1,2 \%$ & $1,1 \%$ & 24.481 & $93,8 \%$ & $5,1 \%$ & $1,1 \%$ & $0,0 \%$ \\
\hline \multicolumn{11}{|l|}{ Sócio ocupado } \\
\hline Dirigentes em geral & 31.359 & $36,8 \%$ & $9,3 \%$ & $27,6 \%$ & $26,3 \%$ & 146.609 & $32,6 \%$ & $14,0 \%$ & $15,6 \%$ & $37,8 \%$ \\
\hline $\begin{array}{l}\text { Profissionais das ciências } \\
\text { e das artes }\end{array}$ & 860.337 & $43,0 \%$ & $18,0 \%$ & $16,5 \%$ & $22,5 \%$ & 1.191 .066 & $38,7 \%$ & $21,2 \%$ & $11,3 \%$ & $28,8 \%$ \\
\hline Técnicos de nível médio & 924.964 & $49,1 \%$ & $17,0 \%$ & $16,7 \%$ & $17,1 \%$ & 994.728 & $44,9 \%$ & $16,1 \%$ & $13,2 \%$ & $25,8 \%$ \\
\hline $\begin{array}{l}\text { Trabalhadores de serviços } \\
\text { administrativos }\end{array}$ & 34.436 & $63,6 \%$ & $10,6 \%$ & $13,9 \%$ & $11,9 \%$ & 49.669 & $42,5 \%$ & $18,5 \%$ & $12,4 \%$ & $26,6 \%$ \\
\hline $\begin{array}{l}\text { Trabalhadores dos } \\
\text { serviços }\end{array}$ & 1.704 .593 & $74,7 \%$ & $10,9 \%$ & $8,7 \%$ & $5,8 \%$ & 1.995 .273 & $62,6 \%$ & $14,2 \%$ & $7,5 \%$ & $15,7 \%$ \\
\hline $\begin{array}{l}\text { Vendedores e prestadores } \\
\text { de serviço do comércio }\end{array}$ & 2.705 .702 & $71,2 \%$ & $8,4 \%$ & $10,7 \%$ & $9,6 \%$ & 2.808 .686 & $58,3 \%$ & $10,9 \%$ & $9,3 \%$ & $21,5 \%$ \\
\hline Trabalhadores agricolas & 746.445 & $81,3 \%$ & $14,8 \%$ & $3,1 \%$ & $0,8 \%$ & 816.851 & $72,6 \%$ & $19,2 \%$ & $3,4 \%$ & $4,8 \%$ \\
\hline $\begin{array}{l}\text { Trabalhadores da produçãa } \\
\text { de bens e serviços e de } \\
\text { reparação e manutenção }\end{array}$ & 4.706 .068 & $76,2 \%$ & $13,4 \%$ & $6,1 \%$ & $4,2 \%$ & 5.293 .280 & $68,1 \%$ & $17,6 \%$ & $4,5 \%$ & $9,8 \%$ \\
\hline Ocupaç̧eses mal definidas & - & - & - & - & - & 3.838 & $55,2 \%$ & $16,9 \%$ & $16,9 \%$ & $11,0 \%$ \\
\hline
\end{tabular}

Fonte: IBGE - Pesquisa Nacional por Amostra de Domicílios - 2009 e 2014. Elaboração do autor. 
Apenas 10,9\% dos trabalhadores por conta própria possuem algum sócio, sendo que, deste total, a maioria possui registro no CNPJ e/ou contribui para a previdência (63,9\%). Quem não possui sócios tende a ser mais informal, percepção que pode ser extraída do retrato de 2014 ou da evolução 2009-2014 (a redução dos conta própria que possuem sócio deu-se num patamar de 1,5\% superior ao observado entre os que não possuem sócio. É importante realizar o acompanhamento desta variável, pois a política de formalização como Microempreendedor Individual não permite que o trabalhador autônomo tenha sócio.

No que diz respeito às características relativas aos grupamentos de atividade e de ocupação em que se insere o trabalhador por conta própria, tecem-se as seguintes observações:

- Cerca de um terço $(31,5 \%)$ dos trabalhadores por conta própria desempenham suas atividades em estabelecimentos fixos fora do domicílio próprio ou do freguês- loja, oficina, galpão, etc. -, e é neste tipo de negócio que se encontra a menor proporção de trabalho informal (36,1\%). Ainda que apresente um grau expressivo de informalidade $(75,2 \%)$, os autônomos que exercem trabalhos em domicílio do empregador, patrão, sócio ou freguês tiveram a maior redução de informalidade entre 2009-2014, na ordem de 14,0\%.

- Atividades ligadas ao comércio e à construção civil ocupam juntas quase a metade $(47,0 \%)$ dos trabalhadores por conta própria do país, com destaque para a alta proporção de empreendimentos informais no setor da construção civil (84,6\% em 2009; 76,1\% em 2014). Em termos proporcionais, trabalhadores ligados ao comércio e reparação experimentaram redução mais expressiva na taxa de informalidade nos últimos cinco anos (queda de 13,2\%).

- Como esperado, ocupações que requerem maior habilidade e qualificação (dirigentes, profissionais das ciências e das artes e técnicos de nível médio) possuem menores proporções de indivíduos em situação de informalidade.

Em síntese, do total dos trabalhadores por conta própria em idade adulta e residente em áreas urbanas (13,3 milhões de indivíduos), 60,6\% são considerados informais por não terem suas atividades registradas no CNPJ nem contribuírem para a previdência social. Apenas 16,1\% dos autônomos observam simultaneamente os dois critérios de formalização adotados neste estudo, enquanto $23,2 \%$ só cumprem um dos requisitos 
- 15,9\% apenas contribuem para a previdência e 7,3\% só possuem o registro no CNPJ.

Se, por um lado, não se pode ignorar o patamar elevado da informalidade entre os autônomos brasileiros, por outro prisma de análise deve ser levada em conta a redução expressiva do fenômeno nos últimos cinco anos (9,8\%). Com o avanço no número de microempreendedores individuais no país (cerca de 5,8 milhões no início de 2016), deve ser observada uma tendência de redução continuada da informalidade entre os trabalhadores por conta própria no Brasil.

No cenário atual, a análise das variáveis escolhidas indica que há uma maior concentração de informalidade entre trabalhadores por conta própria negros e pardos, mais jovens, residentes nas regiões Norte e Nordeste, com baixa escolaridade, que atuam no ramo da construção civil e que desempenham suas atividades em vias públicas ou em locais designados pelos clientes que contratam seus serviços.

Para que a política de formalização via microempreendedor individual produza resultados efetivos para o bem-estar da sociedade brasileira, faz-se necessária uma ação estratégica e coordenada para reduzir a disparidade entre a informalidade dos catadores e doutores, ou em outros termos, de trabalhadores menos e mais qualificados, conforme demonstrado na tabela abaixo.

Tabela 5 Taxa de informalidade dos trabalhadores por conta própria no Brasil urbano e adulto -20 atividades mais representativas -2014

\begin{tabular}{|c|c|c|c|c|c|}
\hline & Total & INF & PREV & CNPJ & PREV+CNPJ \\
\hline Total de trabalhadores por conta própria & 13.300 .000 & $60,6 \%$ & $15,9 \%$ & $7,3 \%$ & $16,1 \%$ \\
\hline $\begin{array}{l}\text { Construção civil - preparação do terreno, construção de edificicios e obras } \\
\text { de engenharia civil, obras de instalações e obras de acabamento }\end{array}$ & 2.848 .983 & $76,1 \%$ & $15,8 \%$ & $2,9 \%$ & $5,1 \%$ \\
\hline Cabeleireiros e outros tratamentos de beleza & 1.038 .407 & $59,2 \%$ & $17,3 \%$ & $6,8 \%$ & $16,6 \%$ \\
\hline $\begin{array}{l}\text { Comércio varejista realizado em postos móveis, instalados em vias públicas } \\
\text { ou em mercados }\end{array}$ & 710.484 & $75,1 \%$ & $13,7 \%$ & $3,3 \%$ & $7,9 \%$ \\
\hline Outros serviços de alimentação - exceto ambulantes & 674.053 & $57,7 \%$ & $10,8 \%$ & $11,5 \%$ & $19,9 \%$ \\
\hline Comércio de produtos alimentícios, bebidas e fumo & 569.185 & $53,2 \%$ & $9,4 \%$ & $11,8 \%$ & $25,5 \%$ \\
\hline Transporte rodoviário de passageiros & 516.391 & $57,2 \%$ & $26,5 \%$ & $4,2 \%$ & $12,1 \%$ \\
\hline Comércio de artigos do vestuário, complementos e calçados & 402.142 & $44,4 \%$ & $8,4 \%$ & $11,2 \%$ & $35,9 \%$ \\
\hline Transporte rodoviário de cargas - exceto de mudanças & 392.698 & $53,7 \%$ & $28,5 \%$ & $5,6 \%$ & $12,1 \%$ \\
\hline Serviços de reparação e manutenção de veículos automotores & 390.229 & $46,4 \%$ & $13,5 \%$ & $12,4 \%$ & $27,6 \%$ \\
\hline
\end{tabular}




\begin{tabular}{|c|c|c|c|c|c|}
\hline & Total & INF & PREV & CNPJ & PREV+CNP] \\
\hline $\begin{array}{l}\text { Atividades jurídicas; de contabilidade; e de pesquisas de mercado } \\
\text { e opinião pública }\end{array}$ & 307.519 & $30,1 \%$ & $28,4 \%$ & $10,9 \%$ & $30,6 \%$ \\
\hline Confecção de artigos do vestuário e acessórios - exceto sob medida & 305.606 & $63,6 \%$ & $22,3 \%$ & $5,1 \%$ & $9,0 \%$ \\
\hline Saúde particular & 226.918 & $21,1 \%$ & $35,5 \%$ & $10,3 \%$ & $33,1 \%$ \\
\hline Representantes comerciais e agentes do comércio & 196.448 & $34,1 \%$ & $10,1 \%$ & $14,4 \%$ & $41,4 \%$ \\
\hline Fabricação de artefatos têxteis a partir de tecidos - exceto vestuário & 194.055 & $78,6 \%$ & $13,2 \%$ & $2,5 \%$ & $5,7 \%$ \\
\hline $\begin{array}{l}\text { Comércio de produtos farmacêuticos, médicos, ortopédicos, odontológicos, } \\
\text { cosméticos e de perfumaria }\end{array}$ & 189.123 & $60,2 \%$ & $13,4 \%$ & $9,3 \%$ & $17,2 \%$ \\
\hline Outras atividades artísticas e de espetáculos & 182.068 & $55,2 \%$ & $13,2 \%$ & $13,4 \%$ & $18,2 \%$ \\
\hline Ambulantes de alimentação & 153.541 & $83,2 \%$ & $12,1 \%$ & $2,2 \%$ & $2,6 \%$ \\
\hline Confecção sob medida de artigos do vestuário e acessórios & 146.574 & $67,0 \%$ & $18,4 \%$ & $3,7 \%$ & $10,9 \%$ \\
\hline Fabricação de outros produtos alimentícios & 139.154 & $76,0 \%$ & $11,9 \%$ & $2,6 \%$ & $9,5 \%$ \\
\hline Pesca e serviços relacionados & 135.581 & $52,7 \%$ & $43,7 \%$ & $1,0 \%$ & $2,6 \%$ \\
\hline
\end{tabular}

Fonte: IBGE - Pesquisa Nacional por Amostra de Domicílios - 2009 e 2014. Elaboração do autor.

\section{Considerações finais}

As propostas teórico-metodológicas que abordam o "informal" e suas inúmeras variações - "setor", "emprego", "economia", etc. - têm como um de seus principais desafios a amplitude do campo de pesquisa em que se inserem. Esse conceito polissêmico busca entender tanto o funcionamento de modos de produção não tipicamente capitalistas utilizados como estratégia de sobrevivência em países periféricos quanto a redução da estabilidade e da proteção social do emprego assalariado em nações desenvolvidas.

Divergências entre as ideias formuladas por escolas de pensamento que tentam explicar a gênese e evolução da informalidade podem ser encaradas de dois modos. Alguns críticos avaliam que se o fenômeno desperta olhares tão conflituosos, seria melhor abandoná-lo ou procurar um novo conceito. Outros pesquisadores enxergam a possibilidade de que essas visões podem ser complementares umas às outras, o que auxiliaria a compreensão mais ampla da informalidade.

Este artigo buscou trilhar o segundo caminho. Ao perceber que boa parte da literatura associava indistintamente o trabalho por conta própria da informalidade, o autor buscou fundamentos teóricos e analíticos que validassem a noção de que não necessariamente todo trabalhador autôno- 
mo deve ser encarado sob o prisma da informalidade. Com o advento do conceito de "economia informal", passa-se a avaliar o fenômeno a partir das relações de emprego (labour approach), complementando a abordagem anterior que tinha como foco de análise as unidades produtivas (enterprise approach) - "setor informal".

Sendo assim, o trabalho por conta própria é obrigatoriamente informal se for analisado exclusivamente a partir do enfoque setorialista, que prioriza as diferenças entre as empresas tipicamente capitalistas e os empreendimentos com produção em pequena escala, baixa produtividade e conduzidos por trabalhadores que compõem o excedente estrutural. Por outro lado, se for utilizado como critério o fato das unidades econômicas e dos trabalhadores estarem - na lei e na prática - cobertos por arranjos formais, nem todo trabalhador por conta própria é informal.

Considerar que o trabalhador por conta própria pode ser caracterizado como formal pelo fato do mesmo possuir registro de sua atividade no CNPJ e contribuir para a previdência social não se configura, necessariamente, um reducionismo a partir da priorização de uma abordagem legalista. $\bigcirc$ que está em jogo é a observação de um "patamar básico de proteção social e o acesso à cidadania tanto para pequenos empregadores como para autônomos e empregados. Não é pela simples formalização, mas pelas condições que ela garante" (Krein; Proni, 2010, p. 34). Em outras palavras, não é pelo simples fato de aderir à política de formalização fazendo uso da figura jurídica do Microempreendedor Individual, mas pela possibilidade de obtenção de alguns direitos anteriormente exclusivos a quem tinha um emprego formal, como a aposentadoria, o auxílio doença, a licença maternidade, entre outros benefícios previstos pela política.

Logo, torna-se cada vez mais imperativo o esforço dos agentes públicos para expandir o grau de cobertura dessa política. $O$ país tem atualmente cerca de 4 milhões de Microempreendedores Individuais formalizados, diante de um universo de aproximadamente 19,8 milhões de trabalhadores por conta própria. A formalização como MEI se configura como uma importante alternativa para que os 13,8 milhões de autônomos que nem contribuem para a previdência nem possuem suas atividades registradas no CNPJ possam sair de uma condição de total instabilidade e desproteção social.

O número elevado de formalizações a partir da figura jurídica do Microempreendedor Individual mostra que há uma tentativa do Estado em ampliar a cobertura social junto ao expressivo contigente de trabalhadores 
por conta própria no Brasil. É preciso avançar, entretanto, em termos de segmentação da estratégia de inclusão e formalização desses indivíduos. $O$ trabalho por conta própria na construção civil e no comércio ambulante de alimentos, por exemplo, possui a maior proporção de indivíduos que nem contribuem para a previdência nem possuem registro no CNPJ entre as 20 atividades mais representativas analisadas neste artigo.

Torna-se necessário, portanto, levar em consideração a heterogeneidade do trabalho por conta própria no país, e isso requer níveis de conhecimento mais aprofundados sobre cada atividade específica, ou ao menos sobre aquelas mais representativas. O estudo de Theodoro (2002), por exemplo, analisa que em Recife os pintores são os trabalhadores da construção civil que mais contribuem para a previdência social. Pamplona (2013), por sua vez, ao analisar o comércio de rua em São Paulo, indica que a solução para o "problema dos ambulantes" envolve tanto o estímulo para que parte dos trabalhadores deixem a atividade (indivíduos com baixa escolaridade, que não dispunham de instalações fixas nem recursos suficientes) quanto o apoio para a permanência regulada de outra parte, composta por "comerciantes que trabalham em suas próprias barracas, ou equipamentos fixos, muitas vezes têm empregados, em alguns casos são contribuintes da Previdência Social e principalmente não desejam deixar a atividade" (Pamplona, 2013, p. 247).

É importante considerar que o esforço em ampliar a cobertura da proteção social para os trabalhadores autônomos via formalização como Microempreendedor Individual não pode ser encarado como solução única para a redução da informalidade. Não pode ser desconsiderado que "existe un segmento de actividades de supervivência cuya formalización poço puede contribuir a su progresso" (Tokman, 2003, p. 29). O Programa de Promoción de la Formalización en América Latina y el Caribe - FORLAC (ILO, 2014) reconhece a importância da figura do Microempreendor Individual para o processo de formalização, mas reforça a necessidade de políticas públicas de ordem macroeconômica que favoreçam a criação de emprego formal.

Outro aspecto importante que pode influenciar a qualidade da política de formalização diz respeito ao que Arbache (2003) classifica como problema de identidade. A fragmentação do trabalho por conta própria em unidades individuais dificulta a formação de entidades representativas que defendam seus interesses junto ao poder público. Neste sentido, Souza (2013) expõe a tentativa frustrada de criação do SindMEI (Sindicato Nacional dos 
Microempreendedores Individuais), justificada pelo fato de que um único sindicato não poderia cobrir os interesses de um segmento tão diverso.

Esse desafio deve ser superado por novos arranjos institucionais e negociações políticas que ampliem a atenção dada ao trabalho por conta própria no país. A formalização não deve ser encarada como um fim em si mesma, e sim como um primeiro passo de inclusão e acesso a patamares básicos de cidadania, como um meio para que as pessoas tenham melhores condições de desenvolver seu potencial produtivo e percebam maior nível de bem-estar.

Ainda que com algumas flutuações, a proporção da população brasileira ocupada no trabalho por conta própria se mantem, de 1970 até o início da atual década (2014), no mesmo patamar: cerca de $20 \%$ dos ocupados. Trata-se, portanto, de uma questão estrutural na configuração do mercado de trabalho do país, e que deve ser compreendida a partir da heterogeneidade que marca esta categoria ocupacional.

Dado esse contexto, a contribuição deste artigo ao debate sobre o trabalho por conta própria e sobre a informalidade consistiu na identificação de um novo campo de pesquisa: os fatores que explicam as diferenças entre os trabalhadores autônomos que se formalizam e os que permanecem na informalidade. Apenas $13,7 \%$ da população urbana e adulta que trabalha por conta própria contribuem para a previdência social e, ao mesmo tempo, possuem suas atividades registradas no CNPJ. O grande desafio para os formuladores da política de formalização consiste na ampliação da taxa de formalidade junto à população negra e parda, mais jovem, residente nas regiões Norte e Nordeste, de baixa escolaridade, que trabalha há pouco tempo, em casa ou na rua, com baixa remuneração e que atua no ramo da construção civil.

O trabalho por conta própria continuará sendo um componente estrutural do mercado de trabalho brasileiro. O Brasil vivenciou na última década um crescimento significativo da proporção do emprego assalariado formal no total de ocupados (9,7\% entre 2001 e 2014), mas a proporção de trabalhadores por conta própria foi reduzida em apenas 1,0\%. Diante desse cenário, a estratégia de desenvolvimento nacional deve incorporar como objetivo a redução das disparidades de bem-estar entre os trabalhadores por conta própria informais e aqueles que se formalizam, para que não haja uma dicotomia tão expressiva como a observada entre catadores e doutores. 


\section{Referências}

ARBACHE, J. S. Pobreza e mercados no Brasil. In: ARBACHE, J. S. Pobreza e Mercados no Brasil: uma análise de iniciativas de políticas públicas. Brasília: CEPAL - escritório no Brasil \& Department for International Development, 2003.

BARBOSA, A. de F. O Conceito de Trabalho Informal, sua evolução histórica e o potencial analítico atual: para não jogar a criança fora junto com a água do banho. In: BARBOSA, A. de F. Marchas e Contramarchas da Informalidade do Trabalho. João Pessoa: Editora Universitária da UFPB, 2011, p.105-159.

BARBOSA FILHO, F. de H.; MOURA, R. L. Evolução recente da informalidade no Brasil: uma análise segundo características da oferta e demanda de trabalho. Texto para discussão n. 17. IBRE/FGV, 2012.

BARTAL, P. et al. Trabalho no governo Lula uma reflexão sobre a recente experiência brasileira. Global University Working Papers, 2010.

CACCIAMALI, M. C. Um estudo sobre o setor informal urbano e formas de participação na produção. Tese de Doutorado. Universidade de São Paulo,1982.

CACCIAMALI, M. C. (Pré-) Conceito sobre o setor informal, reflexões parciais, embora instigantes. Comentários ao artigo. Econômica, v. 9, 2007.

CÂMARA DOS DEPUTADOS. Comissão de Desenvolvimento Econômico, Indústria e Comércio. Cartilha do microempreendedor individual. Brasília: Câmara dos Deputados. Edições Câmara, 2010.

CHAHAD, J. P. Z; CACCIAMALI, M. C. As transformações estruturais no setor de transporte rodoviário ea reorganização no mercado de trabalho do motorista de caminhão no Brasil. Revista da ABET, v. 5, n. 2, 2005.

CHEN, M. A. The informal economy: definitions, theories and policies. WIEGO Working Paper, n. 1, Manchester: 2012.

CORSEUIL, C. H; REIS, M. C. Uma definição alternativa para ocupação informal. Mercado de Trabalho, v. 46, p. 30, 2011.

CORSEUIL, C. H; NERI, M. C.; ULYSSEA, G. L. Uma análise exploratória dos efeitos da política de formalização dos microempreendedores individuais. Nota Técnica. Brasília: IPEA, 2013.

COSTA, M. da S. Trabalho informal: um problema estrutural básico no entendimento das desigualdades na sociedade brasileira. Caderno CRH, v. 23, n. 58, 2010.

CURI, A. Z; MENEZES-FILHO, N. A. O mercado de trabalho brasileiro é segmentado? Alterações no perfil da informalidade e nos diferenciais de salários nas décadas de 1980 e 1990. Estudos Econômicos. (São Paulo), v. 36, n. 4, p. 867-899, 2006.

FEIJO, C.; DO NASCIMENTO, D.; DE SOUZA, A. Quão heterogêneo é o setor informal brasileiro? Uma proposta de classificação de atividades baseada na Ecinf. Revista de Economia Contemporânea, v. 13, n. 2, p. 329-354, 2009.

FURTADO, A. Economia informal e trabalho informal: duas faces da mesma moeda? Brasília: Câmara dos Deputados, 2004. 
GOMES, R. O autoemprego no Brasil: análise dos fatores determinantes. Dissertação de Mestrado. Pontifícia Universidade Católica de São Paulo, 2009.

HART, K. Informal income opportunities and urban employment in Ghana. The Journal of Modern African Studies, v. 11, n. 01, p. 61-89, 1973.

HART, K. Informal economy. In: HART, K.; LAVILLE, J.; CATTANI, A. D. (Orgs.). The human economy: a citizen's guide. Cambridge: Polity Press, 2010.

HOLZMANN, L. O Trabalhador por Conta Própria no Brasil. Revista Paranaense de Desenvolvimento-RPD, v. 34, n. 124, p. 119-137, 2013.

HUGON, P. O setor informal: balanço de 25 anos de trabalho. Ensaios FEE, v. 18, n. 2, p. 3263, 1997.

HUSSMANNS, R. Measuring the informal economy: from employment in the informal sector to informal employment. Working paper, n. 53. Geneva, 2004

INSTITUTO BRASILEIRO DE GEOGRAFIA E ESTATÍSTICA. Pesquisa Nacional por Amostra de Domicílios: síntese de indicadores 2009. Rio de Janeiro: IBGE, 2010.

INSTITUTO BRASILEIRO DE GEOGRAFIA E ESTATÍSTICA. Pesquisa Nacional por Amostra de Domicílios: síntese de indicadores 2014. Rio de Janeiro: IBGE, 2015.

INTERNATIONAL LABOUR OFFICE. Employment, incomes and equality: a strategy for increasing productive employment in Kenya. International Labour Office, 1972.

INTERNATIONAL LABOUR OFFICE. Resolución sobre las estadísticas del empleo em el sector informal, adoptada por la decimoquinta Conferencia Internacional de Estadísticos del Trabajo (enero de 1993). In: Current International Recommendations on Labour Statistics, 2000 Edition. Geneva: ILO, 2000.

INTERNATIONAL LABOUR OFFICE. Decent work and the informal economy. Report of the Director-General; International Labour Conference, 90th Session; Report IV. International Labour Office, Geneva, 2002.

INTERNATIONAL LABOUR OFFICE. Diretrices sobre uma definición estadística de empleo informal, adoptadas por la decimoséptima Conferencia Internacional de Estadísticos del Trabajo (noviembre - diciembre de 2003). In: Current International Recommendations on Labour Statistics, 2003 Edition. Geneva: ILO, 2003.

INTERNATIONAL LABOUR OFFICE. Experiencias recientes de formalización en países de América Latina y el Caribe. In: Notas sobre formalización - Programa de promoción de la formalización en América Latina y el Caribe. ILO, 2014.

KON, Anita. Diversidades nas condições de informalidade do trabalho brasileiro. Encontro nacional de economia ANPEC, v. 32, 2004.

KREIN, J. D.; PRONI, M. W. Economia informal: aspectos conceituais e teóricos. Escritório da OIT no Brasil - Brasília: OIT, 2010.

MATSUO, M. Trabalho informal e desemprego: desigualdades sociais. Tese de Doutorado. Universidade de São Paulo, 2009.

MATTOS, F. A. M. Lições do capitalismo organizado: o mercado de trabalho do pós-guerra nos países capitalistas centrais. Ensaios FEE, v. 18, n. 1, p. 122-147, 1997.

NORONHA, E. "Informal", ilegal, injusto: percepções do mercado de trabalho no Brasil. 
Revista Brasileira de Ciências Sociais, v. 18, n. 53, 2003.

PAMPLONA, J. B. Mercado de trabalho, informalidade e comércio ambulante em São Paulo. Revista Brasileira de Estudos de População, v. 30, n. 1, p. 225-249, 2013.

PORTAL DO EMPREENDEDOR. Acumulado Mês/Dia - Inscritos Total. 10/05/2014. Disponível em: <http://www.portaldoempreendedor.gov.br/mei-microempreendedor-individual/lista-dos-relatorios-estatisticos-do-mei>. Acesso em: 10/06/2014.

PRANDI, J. R. O trabalhador por conta própria sob o capital. Edições Símbolo, 1978

RAMOS, C. A. Setor informal: do excedente estrutural à escolha individual. Marcos interpretativos e alternativas de política. Econômica, v. 9, n. 1, p. 115-138, 2007.

SANTOS, M. Pobreza urbana. São Paulo: Hucitec, 1979.

SANTOS, A. L. Trabalho informal nos pequenos negócios: evolução e mudanças no governo Lula. In: SANTOS, A. L.; KREIN, J. D.; CALIXTRE, A. B. (Orgs.) Micro e pequenas empresas: mercado de trabalho e implicação para o desenvolvimento. Rio de Janeiro: IPEA, 2012. Cap. 5, p. 167-210.

SERVIÇO BRASILEIRO DE APOIO ÀMICRO E PEQUENA EMPRESA (SEBRAE). 3 Anos da Lei Geral da micro e pequena empresa. Brasília, 2010.

SETHURAMAN, S. V. El sector urbano no formal: definición, medición y política. Revista Internacional del Trabajo, v. 94, n. 1, p. 77-90, 1976.

SOUZA, I. A. J. Empreendedorismo, inclusão produtiva e progressão social: possibilidades participativas no Plano Brasil Sem Miséria. Revista Desenvolvimento Econômico Territorial, $2^{a}$ edição, p. 15-29, 2013.

TANZI, V. A economia subterrânea, suas causas e consequências. Economia subterrânea: uma visão contemporânea da economia informal no Brasil. Rio de Janeiro: Elsevier, 2009.

THEODORO, M. et al. Atividades informais: evolução e condicionantes atuais - o caso dos trabalhadores autônomos do Recife. Texto para Discussão, n. 864. Brasília: IPEA, 2002.

THEODORO, M. et al. As características do mercado de trabalho e as origens do informal no Brasil. Questão social e políticas sociais no Brasil contemporâneo. Brasília: IPEA, 2005.

TOKMAN, V. E. El sector informal: quince años después. El Trimestre Económico, p. 513-536, 1987.

TOKMAN, V. E. De la informalid a la modernidad. ILO - Boletín CINTEFOR, n. 155, 2003.

VIANNA, M. C. S. A discussão histórica da informalidade: significados e formas de representação. Tese de Doutorado. Instituto Universitário de Pesquisas do Rio de Janeiro, 2006.

\section{Sobre os autores}

Carlos Eduardo Pinto Santiago - carlos.pinto@sebrae.com.br

Serviço Brasileiro de Apoio à Micro e Pequena Empresa - SEBRAE, Brasília, DF.

Ana Maria Nogales Vasconcelos - nogales@unb.br

Departamento de Estatística,Pós-graduação em Desenvolvimento, Sociedade e Cooperação Internacional, Universidade de Brasília, Brasília, DF

\section{Sobre 0 artigo}

Recebido em 25 de agosto de 2014. Aprovado em 16 de março de 2016. 